IZA DP No. 7046

What Explains the Decline in Wage Mobility in the German Low-Wage Sector?

Bodo Aretz

Nicole Gürtzgen

November 2012 


\title{
What Explains the Decline in Wage Mobility in the German Low-Wage Sector?
}

\author{
Bodo Aretz \\ ZEW Mannheim \\ and IZA
}

\section{Nicole Gürtzgen}

ZEW Mannheim

\section{Discussion Paper No. 7046 \\ November 2012}

\author{
IZA \\ P.O. Box 7240 \\ 53072 Bonn \\ Germany \\ Phone: +49-228-3894-0 \\ Fax: +49-228-3894-180 \\ E-mail: iza@iza.org
}

\begin{abstract}
Any opinions expressed here are those of the author(s) and not those of IZA. Research published in this series may include views on policy, but the institute itself takes no institutional policy positions. The IZA research network is committed to the IZA Guiding Principles of Research Integrity.

The Institute for the Study of Labor (IZA) in Bonn is a local and virtual international research center and a place of communication between science, politics and business. IZA is an independent nonprofit organization supported by Deutsche Post Foundation. The center is associated with the University of Bonn and offers a stimulating research environment through its international network, workshops and conferences, data service, project support, research visits and doctoral program. IZA engages in (i) original and internationally competitive research in all fields of labor economics, (ii) development of policy concepts, and (iii) dissemination of research results and concepts to the interested public.
\end{abstract}

IZA Discussion Papers often represent preliminary work and are circulated to encourage discussion. Citation of such a paper should account for its provisional character. A revised version may be available directly from the author. 


\section{ABSTRACT \\ What Explains the Decline in Wage Mobility in the German Low-Wage Sector?*}

In this paper, we study how wage mobility in the low-wage sector has changed in western Germany between 1984 and 2004. Using German individual register data, we document a clear upward trend in the persistence of low-wage employment for both men and women. Next to compositional shifts of the low-wage sector relative to the high-wage sector, this trend may be explained by an increase in "genuine" state dependence, which occurs if low-wage employment today causes low-wage employment in the future for reasons of, e.g., stigmatization or human capital depreciation. To isolate the latter, we model low-pay transitions by estimating a series of multivariate probit models. We address the initial conditions problem and the endogeneity of earnings attrition in our estimation approach by accounting for the selection into low-wage employment and earnings retention. Our findings for men and women point to an upward trend of genuine state dependence among low-paid workers especially since the beginning of the 1990s. Using decomposition techniques, we show that between 35 and 54 per cent of the increase in genuine state dependence during the 1990s is accounted for by compositional effects.

JEL Classification: C23, J31, L13

Keywords: $\quad$ wage mobility, trivariate probit, administrative data

Corresponding author:

Bodo Aretz

Centre for European Economic Research (ZEW)

Department of Labor Economics, Human Resources and Social Policy

L7 1

68161 Mannheim

Germany

E-mail: aretz@zew.de

\footnotetext{
* We thank Melanie Arntz and Anja Heinze for providing us with programming routines as well as Verena Niepel, Arne Uhlendorff and Steffen Reinhold for fruitful discussions and helpful comments. Financial support from the German Science Foundation (DFG) is gratefully acknowledged (Grant-No. FR 715/9-1).
} 


\section{Introduction}

A large body of academic work has documented a sharp increase in earnings inequality particularly in the Anglo-Saxon countries over the last three decades (e.g. Acemoglu 2003, Gosling et al. 2000, Levy and Murnane 1992). However, as long as individuals are able to move up the earnings distribution, a high degree of cross-sectional earnings inequality is likely to exaggerate the extent of inequality over a working life. Thus, any analysis of the evolution of lifetime inequality requires investigating the evolution of both inequality and mobility. For example, a rise in wage mobility could mitigate an increase in cross-sectional earnings inequality because, in that case, a position at the bottom of the distribution would be of more temporary nature. Conversely, if a rise in earnings inequality were accompanied by a decline in mobility, inequality over a working lifetime would increase due to more persistent positions in the earnings distribution.

Even though there is a large literature that addresses both the evolution of inequality and mobility over time (e.g., Cardoso 2006, Dickens 2000, Gottschalk 1997, Kopczuk et al. 2010), little is known about the determinants underlying the evolution of wage mobility. This is particularly relevant as a number of authors has documented a widening in the distribution of labor earnings that is accompanied by a decline in mobility, giving rise to a larger persistence of low-wage employment (see Buchinsky and Hunt (1999) for the U.S., Cardoso (2006) for Portugal and Dickens (2000) for the U.K.). From a welfare perspective, a high degree of low-pay persistence is of particular concern as it tends to marginalize lowwage workers in the long run. As a result, the determinants of low-pay persistence are of considerable interest to policy-makers. For instance, a decline in low-wage mobility that is accounted for by an increase in the fraction of those without educational attainment would call for appropriate policy interventions aiming at improving these characteristics. In contrast, if a decline in low-wage mobility was caused by increasing state dependence due to stigmatization effects, policy measures aiming at improving observable attributes of low-wage workers would be less likely to succeed.

The purpose of the present paper is therefore to fill this gap and to investigate the determinants of the evolution of wage mobility. Using German administrative data, we 
focus on the western German low-wage sector, which is particularly interesting for several reasons. First, while the German wage structure has long been considered relatively stable at lower percentiles (Prasad 2004), the past two decades have seen a clear tendency towards more earnings inequality at the bottom end of the earnings distribution (Dustmann et al. 2009, Kohn 2006). As a consequence, the low-wage sector has increasingly grown in importance. Second, there is evidence that wage mobility has been declining over the last decades (see Gernandt 2009 and Riphahn and Schnitzlein 2011). However, as mentioned above, this does not necessarily imply a larger degree of persistence in terms of "true" or "genuine"state dependence of low-wage employment, which may occur if low-wage employment today causes low-wage employment in the future for reasons of stigmatization or human capital depreciation. ${ }^{1}$ Alternatively, a larger degree of persistence may also be the result of a more unfavorable composition of the low-wage sector. The large extent of selection into low-wage employment has been documented by a number of studies dealing with the determinants of wage mobility. A key finding that emerges from this literature is that the extent of genuine state dependence is often considerably reduced once observable attributes and selection into low-wage employment are accounted for (see Cappellari 2002, 2007, Stewart and Swaffield 1999). The overall aim of our analysis is therefore to explore to what extent the observed decline in German low-wage mobility reflects a rise in "true" state dependence by distinguishing the evolution of genuine state dependence from pure composition effects.

The data we use to address these questions stem from the IAB Employment Subsample 1975-2004 (IABS). This administrative data set is a two per cent subsample of the German Employment Statistics Register, which is based on reports from employers in compliance with the notifying procedure for the German social security system. The Employment Statistics Register offers information on individual wage records and a number of individual characteristics for the whole population of employees who are covered by the German social security system. The IABS provides a useful basis for exploring the evolution of the determinants of wage mobility for several reasons. First, the data allow us to retrieve

\footnotetext{
${ }^{1}$ Using German household data from the GSOEP, Uhlendorff (2006) finds evidence for true state dependence of low-pay jobs. In contrast to Uhlendorff (2006), who looks at pooled transitions over the observation period 1998 to 2003, we focus on the evolution of true state dependence over time.
} 
a great deal of reliable information on workers' previous employment histories, which will be used to model the selection of individuals into the low-wage sector. Second, due to the administrative nature of the IABS, the problem of panel attrition is considerably reduced as the data track individuals over time as long as they are either employed or, alternatively, unemployed with transfer payments. Even though our data feature less panel attrition than survey data, we still face the problem of non-random earnings retention as individuals may become voluntarily or involuntarily unemployed and may fall out of the earnings distribution. Because this dropout is likely to be non-random, we follow the approach of Cappellari and Jenkins (2006) and Cappellari (2007) by estimating a series of trivariate probit models, which not only account for the selection into low-wage employment, but additionally model non-random earnings retention. To do so, we will take advantage of the precise information on workers' employment histories in order to find appropriate exclusion restrictions that govern both the process of earnings retention and the initial conditions process.

The remainder of the paper proceeds as follows. Section 2 provides a description of the data and some descriptive results. Section 3 presents the empirical analysis. While Sections 3.1. and 3.2. spell out the estimation strategy and define the measure of state dependence, Section 3.3. presents the empirical results. The final Section 4 concludes.

\section{Descriptive Empirical Analysis}

\subsection{Data and Variable Description}

The data for our analysis are taken from the regional file of the IAB employment subsample 1975-2004 (IABS). This administrative data set, which is described in more detail by Drews (2008), contains a 2 per cent random sample of all social security records spanning the time period 1975 to 2004. It includes employment records subject to social security contributions as well as unemployment records with transfer receipt. The data is representative of all workers subject to the German social security system and covers approximately 80 per cent of the German workforce. Self-employed workers, civil servants 
and individuals currently doing their military service are not included in the data set. We restrict our analysis to western Germany as eastern Germany experienced profound political and structural changes during our observation period. We further restrict our sample to individuals aged 20 to 55 and confine our analysis to the years 1984 to 2004 due to a structural break concerning the wage information which took place in 1984 . The $I A B S$ provides individual information on (daily) wage records, workers' employment histories and a number of individual characteristics such as age, education, nationality and occupational status. Since the data set is comprised out of spell data, the data allow us to retrieve a large number of variables used to proxy the stability of workers' employment histories. In particular, the data allow us to measure tenure at the current employer, the number of previous un- and non-employment spells, the number of previous employers, the number of employment interruptions at the current employer as well as the cumulative duration of previous un- and non-employment spells. A full description as well as descriptive statistics of the variables used in our analysis can be found in Tables B1 and B2 in the Appendix.

Although the $I A B S$ provides a great deal of information on workers' employment histories, the data set has some disadvantages as well. First, the data set provides information on daily wages. While we observe an individual's full-time or part-time status (defined as working less than 30 hours per week), the data lack explicit information on the number of hours worked. For this reason, we restrict our sample to full-time workers. Second, the data do not allow a distinction between involuntarily unemployed individuals without transfer receipt and individuals who left the labor force or who became self-employed or civil servants. To distinguish more precisely between voluntary and involuntary unemployment, we follow the assumptions proposed by Lee and Wilke (2009) about when the state of unemployment is reached. Further information on the definition of un- and nonemployment spells as well as on adjustments of the wage and the education information can be found in Appendix B. 


\subsection{Definition of Low-Pay Status}

To study the evolution of wages in the low-wage sector, we define the low-pay status as earning less than two thirds of the median (full-time) wage. This definition has been used in several other studies (e.g. OECD 1998, Stewart and Swaffield 1999 and European Commission 2004). In order to calculate the low-pay threshold for each year, we consider only spells which include the set date June 30 th. $^{2}$ For each year of our observation period, we start from the population of full-time employed workers for whom we define the lowpay status and the respective pay and employment status five years later. This gives rise to 16 relevant transition periods $(1984 / 1989,1985 / 1990, \ldots, 1999 / 2004)$. The lowor high-pay status is only defined for those who stay full-time employed five years later. We therefore construct a dummy measuring full-time earnings retention, which takes on the value of zero if individuals fall out of the full-time earnings distribution (i.e. become part-time employed, apprentices, involuntarily unemployed or non-employed).

\subsection{The Evolution and Pattern of Low-Pay Transitions}

In line with the definition of Section 2.2, Figure 1 displays the fraction of low paid individuals among all full-time employees for the years 1984 to 2002. The figure shows that the extent of the low-wage sector was quite stable in Germany until the mid nineties with a slightly decreasing trend until 1996. After that, the low-wage sector experienced a clear upward trend: in 2002, the rate of low-wage earners was 14.9 per cent, 14 per cent higher than in $1996 .^{3}$ As shown in Figure 2, the overall increase was fully made-up by male workers. Among them, the share of low paid workers, which was in the range of 5 to 6 per cent between 1984 and 1996, increased to 8 per cent in 2002. In contrast, the share of low paid women dropped from 33 per cent in 1985 to 28 per cent in 2002. Obviously, however, female workers still exhibit a much higher probability of being low paid than male workers. Compared with workers from the high-wage sector, low paid individuals

\footnotetext{
${ }^{2}$ Note, however, that we exploit the full spell structure of the data to construct information on individuals' employment histories. Weighting the wage information by the length of the spell did not alter the results substantially.

${ }^{3}$ This development confirms earlier results by Rhein et al. (2005), who find a very similar evolution of low-wage employment using the same data set for the years between 1990 and 2001. Bosch and Kalina (2007), also using the same data set, yield similar results, though at a slightly higher low-wage level.
} 
are on average four years younger, less well educated and are more likely to be of foreign nationality (see Table B2 in the Appendix). Also, as one would expect, total previous unand non-employment duration periods have on average been longer for individuals in the low-wage sector, whereas their job tenure is on average shorter than that for individuals working in the high-wage sector.

Figure 1: Share of low-wage earners in the total population, $1984-2002$

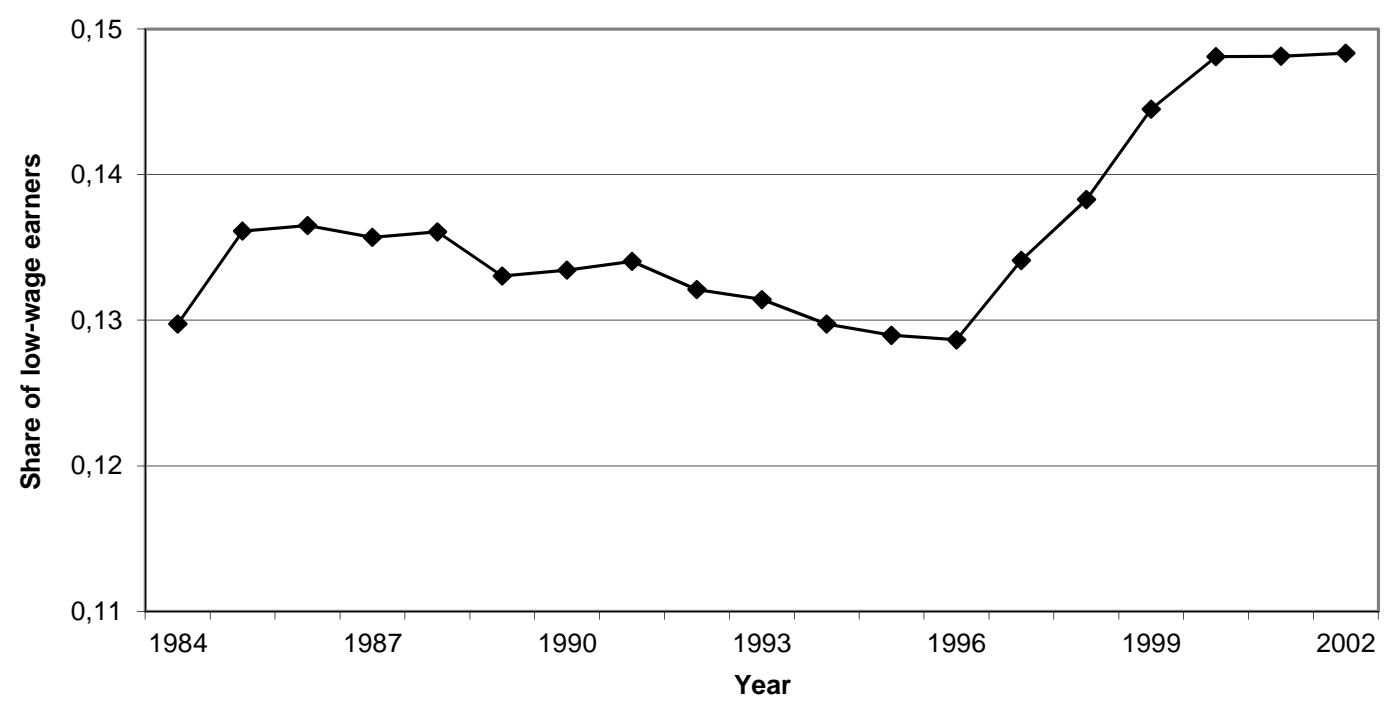

In order to describe the overall pattern of the evolution of low-wage persistence, we calculate a measure of aggregate state dependence $(A S D)$ for each year. This measure is defined as the difference between the probability of staying in the low-wage sector and the probability of entering the low-wage sector five years later, i.e. $A S D=$ $\operatorname{Pr}\left(L_{t}=1 \mid L_{t-5}=1\right)-\operatorname{Pr}\left(L_{t}=1 \mid L_{t-5}=0\right)$. Note that this measure does not account for the heterogeneity across formerly low and high paid workers. Later in our analysis, we will therefore attempt to distinguish this measure from the degree of genuine state persistence $(G S D)$. This is the measure of "true" persistence we are ultimately interested in and will be defined as the difference in transition probabilities conditional on being initially low and high paid, respectively, therefore providing a measure of differences in price effects of observables across the two groups (see Section 3.2). 
Figure 2: Share of low-wage earners in the total population by sex, $1984-2002$

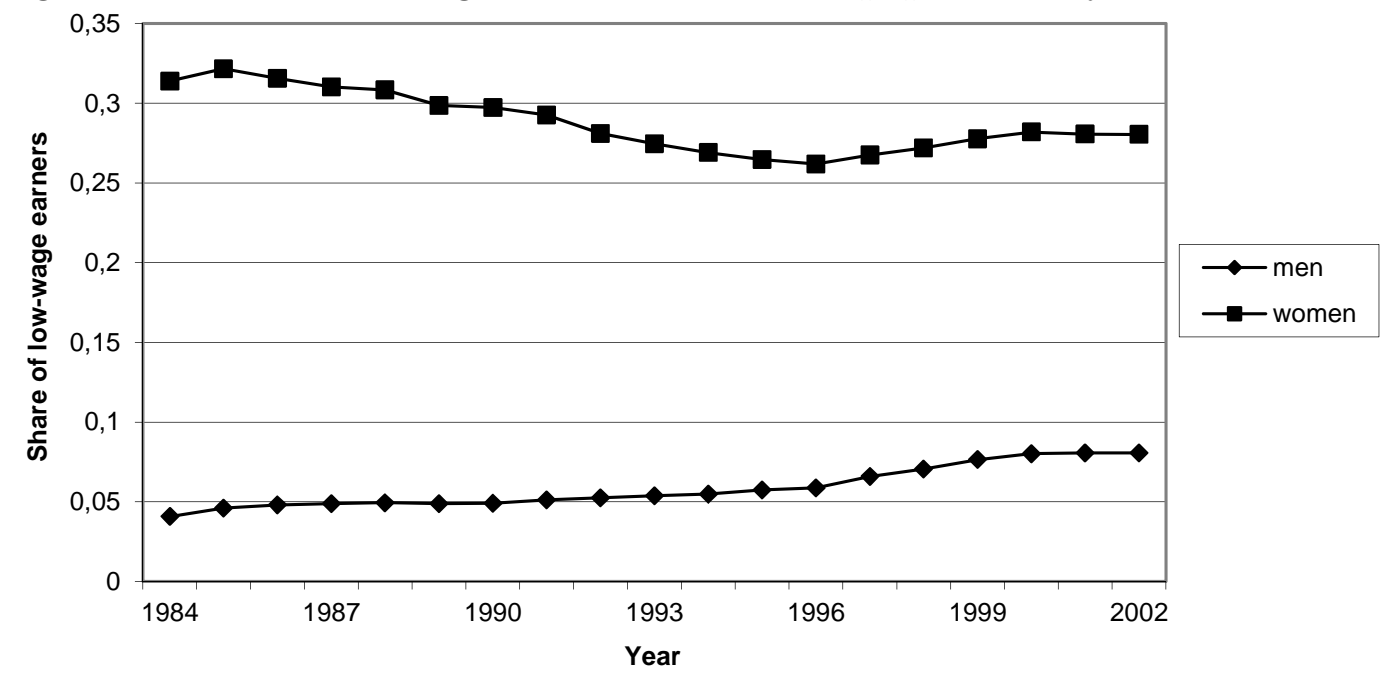

Figure 3 illustrates the evolution of $A S D$ between 1984 and 1999 for males and females. As the probability of entering the low-wage sector is typically close to zero, the extent of $A S D$ is mainly determined by the persistence probability. In 1984, for example, the overall persistence probability was 50 per cent, i.e. one out of two individuals who earned a low wage and still worked five years later kept his or her low-pay status. The probability of moving from high to low pay, however, was very small in 1984, with only every 20th woman and approximately every 100th man entering the low-wage sector. Figure 3 reveals that the level of $A S D$ is about 20 percentage points higher for women than for men. This means that men are considerably less likely to stick to a low-wage job. The development of $A S D$ was quite similar for both sexes, though. Women experienced a larger decrease in $A S D$ in the mid 1980s than men, with both sexes reaching their lowest value in the year 1987 with an $A S D$ of 26 per cent for males and an $A S D$ of 49 per cent for females. Since 1987, $A S D$ has been rising continuously with only a slight attenuation period during the mid 1990s. In 1999, the male $A S D$ amounted to 45 per cent, whereas women faced an $A S D$ of 65 per cent. Thus, (western) Germany has experienced a distinct shift towards a higher degree of low-wage persistence in the last 15 years of the 20th century.

What determines the extent of $A S D$ ? Turning to the association between low-pay persistence and observable attributes, Figure 4 provides the evolution of $A S D$ by different 
Figure 3: Aggregate state dependence by sex, 1984 - 1999

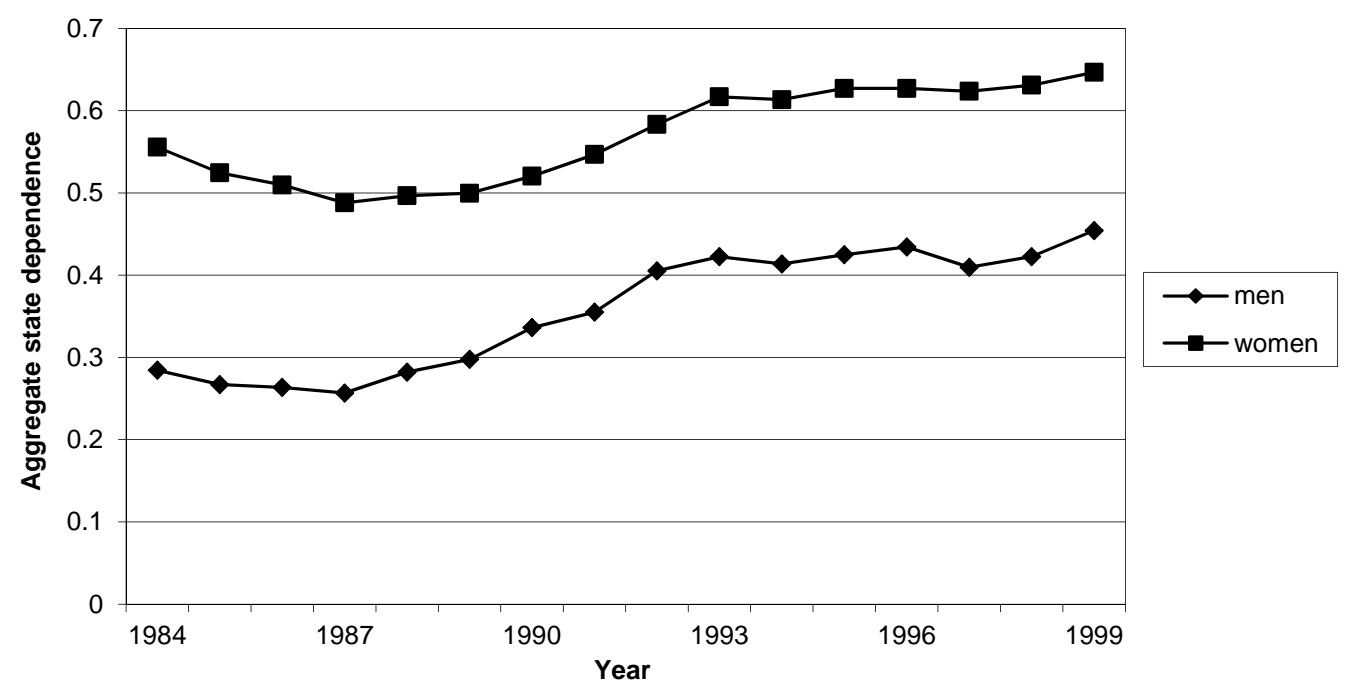

age groups. ${ }^{4}$ The figure illustrates that there are remarkable differences across groups, with younger and less experienced workers exhibiting considerable less $A S D$ than older and more experienced workers. While the difference between the probabilities of remaining low paid and entering low pay was 29 per cent for workers under the age of 25 in 1984 , workers older than 50 years faced a much higher $A S D$ (78 per cent). By 1999, this difference had only slightly decreased. However, the share of old workers in the low-wage sector is by far smaller than the share of young workers below 26 years (see Figure 5). Averaged over the whole observation period, only 3 (27) per cent of male (female) workers above 50 years earned a low wage, whereas 18 (41) per cent of the young workers below 26 years were low paid. In other words, younger workers have a higher probability of earning a low wage but are, at the same time, more likely to move up the wage ladder. Once, however, older workers face a low-wage job, it is much harder for them to escape the low-wage sector. Note that this is consistent with the concave shape of age-earnings profiles typically reported in the literature (see e.g. Murphy and Welch, 1990). ${ }^{5}$ With respect to an individual's tenure, the interpretation works similar (see Figure A1 in the Appendix). The shorter the tenure at the current job is, the higher is the likelihood of earning a low wage (Figure A2) and - on the other hand - the lower will be the extent of

\footnotetext{
${ }^{4}$ For illustration purposes, figures regarding the age variable are shown in the main text. All remaining figures can be found in Appendix A.

${ }^{5}$ For Germany, recent evidence on age-earnings profiles is provided by Bönke et al. (2011).
} 
$A S D$.

The level of education is also clearly related to the degree of state dependence: the better an individual is educated the lower is his or her $A S D$. Figure A3 reveals for both sexes that while the $A S D$ for the high and low-skilled increased only very slightly over our observation period, medium-skilled workers experienced a much larger increase in their $A S D .{ }^{6}$ Interestingly, the $A S D$ level of medium-skilled workers has converged to the $A S D$ level of the low-skilled - a development which can be observed for men as well as for women. Put differently, medium-skilled workers, once earning a low wage, seemed to face about the same risk of being caught in the low-wage sector as their low-skilled counterparts in 1999. As Figure A4 points out, however, the share of medium-skilled men (women) is with 5 (28) per cent substantially lower than the share of low-skilled individuals in the low-wage sector (13 per cent for men, 38 per cent for women).

Figure 4: Aggregate state dependence by age group, 1984 - 1999

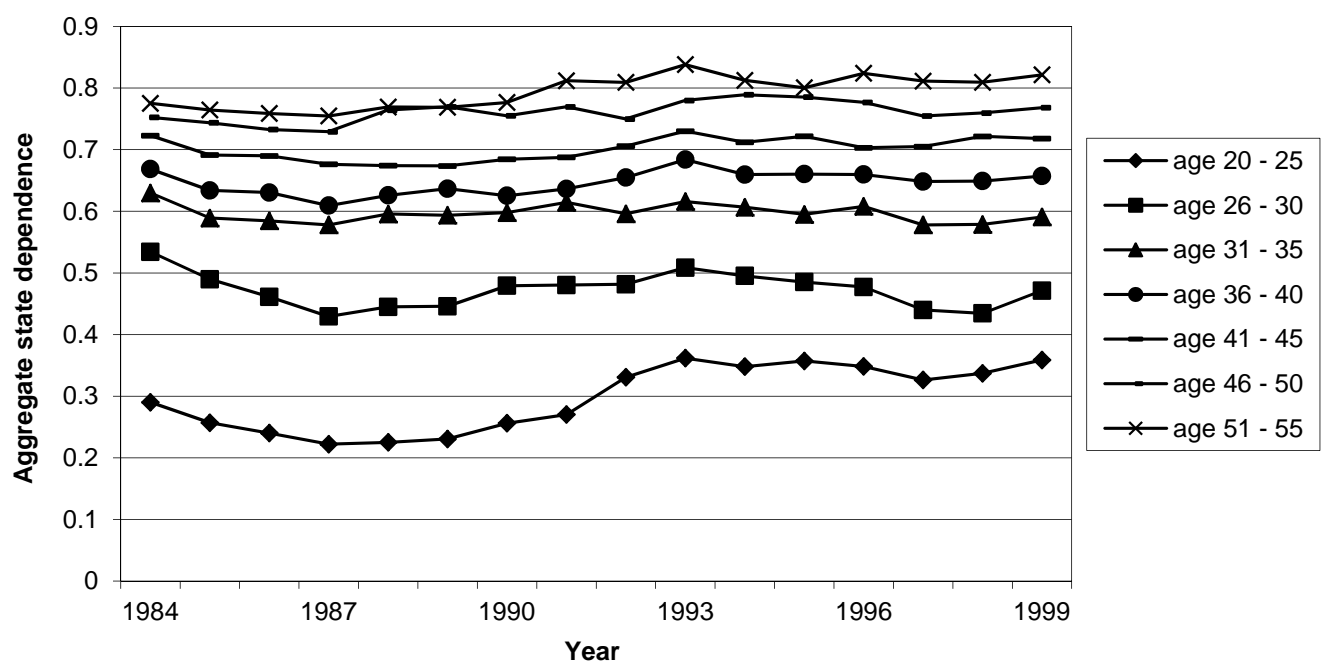

There are further observable characteristics that are associated with different levels of $A S D$. With respect to nationality, for example, Figure A5 reveals that foreign individuals have long faced a larger risk of sticking to a low-wage job. By the end of the observation period in 1999, however, the $A S D$ for workers of German nationality had converged to the level of their foreign counterparts for both males and females. Such a convergence can

\footnotetext{
${ }^{6}$ The spikes in the $A S D$ of high-skilled low paid males can be explained by the small number of observations ( $<100$ per year).
} 
not be found when comparing the development of $A S D$ of blue- and white-collar workers (see Figure A6). Over the whole observation period, the $A S D$ of blue-collar workers has remained about 10 percentage points higher than the $A S D$ of white-collar workers. This pattern holds for male as well as for female workers.

Figure 5: Mean share of low-wage earners by age group and sex, 1984 - 2002

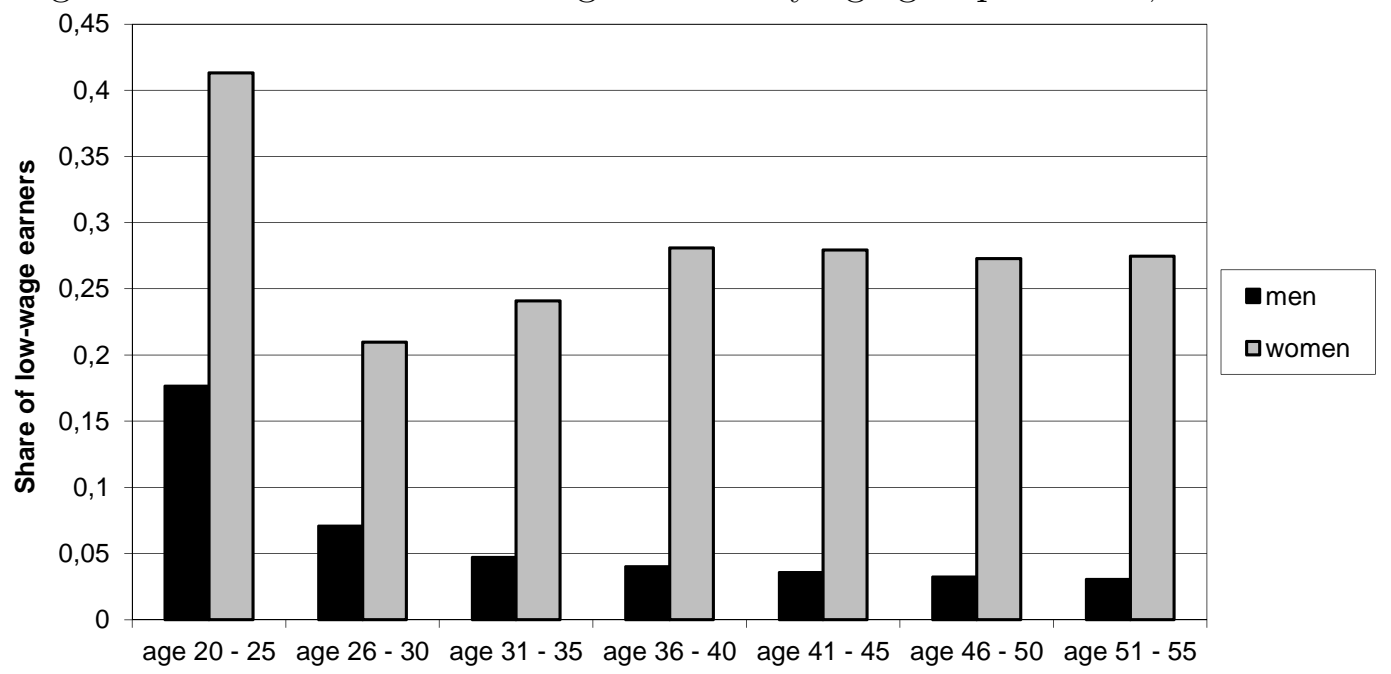

Why did the overall aggregate state dependence increase over time? Besides factors like business cycle effects or other macroeconomic developments, one possible explanation could be a change in the composition of the low-wage sector that caused the extent of $A S D$ to rise. To investigate such possible composition effects, it is instructive to depict the evolution of some selected observable attributes in the low-wage sector relative to the respective development in the high-wage sector. As can be seen from Figure 6 for males and Figure 7 for females, the share of young workers below the age of 26 among the low paid decreased markedly during the last decades. While the proportion of young female workers in the low-wage sector dropped from 40 per cent to 19 per cent over the observation period, the decrease was even larger for male workers below the age of 26 . For the latter, the corresponding share fell from 52 per cent in 1984 to 24 per cent in 2002 . This is a much more pronounced decline compared to the development in the high-wage population where the share of young male (female) workers dropped from 13 to 6 (24 to 10) per cent between 1984 and $2002 .^{7}$ Not only the demographic change drives this

\footnotetext{
${ }^{7}$ The figures of the age and tenure evolution of the high-wage sector are available from the authors upon request.
} 
development. The decision to acquire higher education was taken more often in Germany in 2000 (34 per cent) than in 1985 (20 per cent) so that a smaller share of workers was available for the labor market below the age of 26 (Federal Statistical Office, 2011). ${ }^{8}$ As a consequence, the sharp decline in the share of young workers among the low paid, who - as seen above - face a lower $A S D$ than the older workforce may have contributed to the overall observed increase in $A S D$ over time.

The development of other observed characteristics, however, works against an increase in $A S D$ over the observation period. The sex composition in the low-wage sector, for example, has shifted distinctly towards more men being low paid. While the share of males in the high paid population remained roughly constant within the range of 71 to 74 per cent, the share of male workers among the low paid has steadily risen from 21 per cent in 1984 to 36 per cent in 2002, see Figure A7. Since male workers, on average, face a lower $A S D$ than female workers (compare Figure 3), this change in the sex composition of the low-wage sector has favored a reduction of the overall $A S D$ over time. ${ }^{9}$

Figure 6: Evolution of the age composition in the low-wage sector 1984 - 2002, men

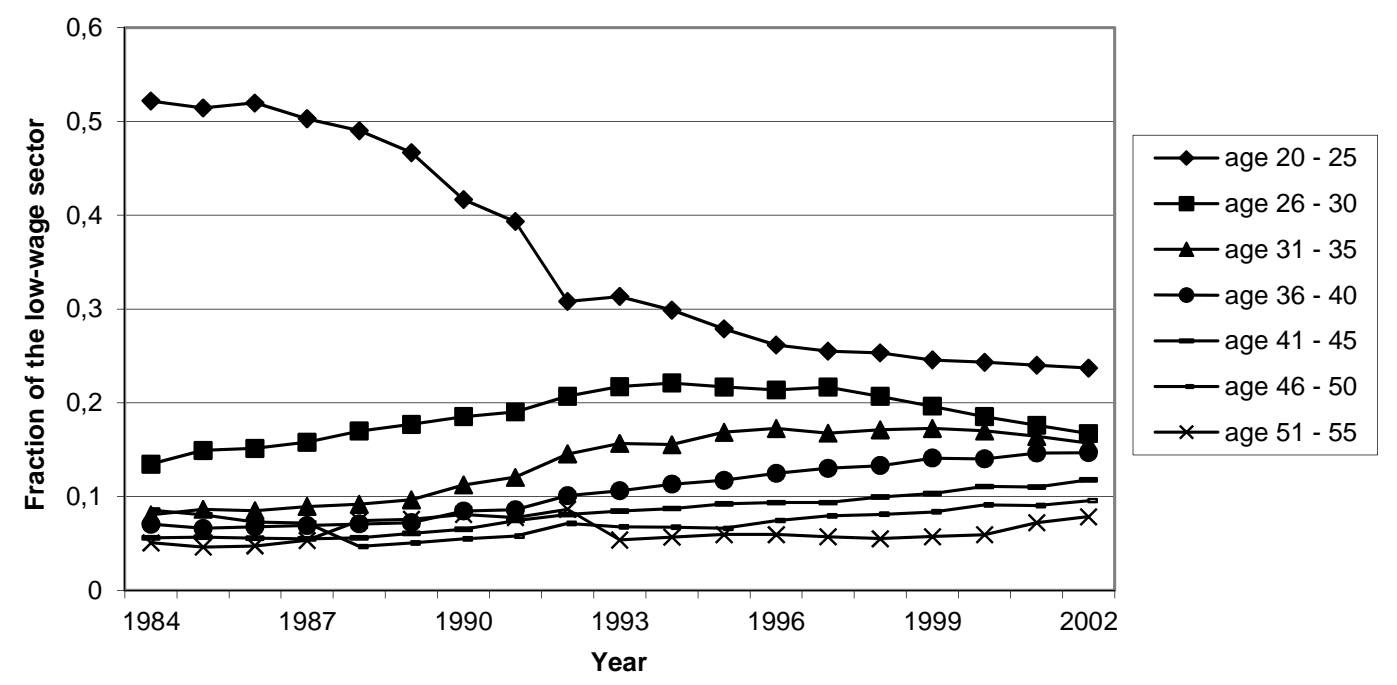

\footnotetext{
${ }^{8}$ Following the definition of the OECD publication "Education at a Glance", the numbers of the Statistical Office are calculated by dividing the absolute number of first-year students by the population of individuals in the typical age range. The number for the year 2000 including the states of eastern Germany.

${ }^{9}$ However, in what follows, we will analyze the evolution of state dependence for men and women separately.
} 
One explanation for the improving situation of women might relate to the decline in the share of low-skilled workers in the female workforce between 1984 and 2002, as can be seen from Figure A8. However, compared to the development in the high-wage sector where the fraction of the low-skilled decreased from 24 to 10 per cent, low paid females experienced a weaker decline in the fraction of low-skilled workers (from 29 to 21 per cent). Male low paid workers exhibit an even less favorable evolution in their skill composition: while in the high-wage sector the fraction of male low-skilled workers declined from 17 to 10 per cent, the corresponding share in the low-wage sector even rose by six percentage points (from 27 to 33 per cent, see Figure A9). Moreover, the low-wage sector experienced a less pronounced increase in the share of high-skilled workers than the high-wage sector, where the fraction of high-skilled doubled between 1984 and 2002 . Overall, the less favorable evolution of the skill composition among low paid workers should have contributed to a rise in $A S D$. However, as medium-skilled workers have steadily approached the $A S D$ level of their low-skilled counterparts over time (compare Figure A3), this price effect is likely to have mitigated the effect of the skill composition on $A S D$ over time.

There are further developments that support a compositional explanation of the rise in $A S D$ over time. As a consequence of the ongoing technological change and the associated structural shift from production to service industries, the share of blue-collar workers (as compared to white-collar workers) declined by about ten percentage points in the high-wage population for both sexes between 1984 and 2002 (see Figure A10). While a reduction in the share of blue-collar workers is also observed for low paid women during the observation period, the opposite is true for male workers in the low-wage sector. Despite the overall decreasing importance of blue-collar jobs, the fraction of blue-collar workers among the low paid increased between 1984 and 2002. As blue-collar workers are more likely to remain low paid (the $A S D$ is - as shown by Figure A6 - ten percentage points higher than for white-collar workers), the male-specific shift towards more low paid blue-collar jobs is likely to have contributed to the rise in $A S D$.

With respect to nationality patterns, Figure A11 illustrates that particularly the lowwage sector has experienced volatile movements over time. While the share of foreign 
Figure 7: Evolution of the age composition in the low-wage sector 1984 - 2002, women

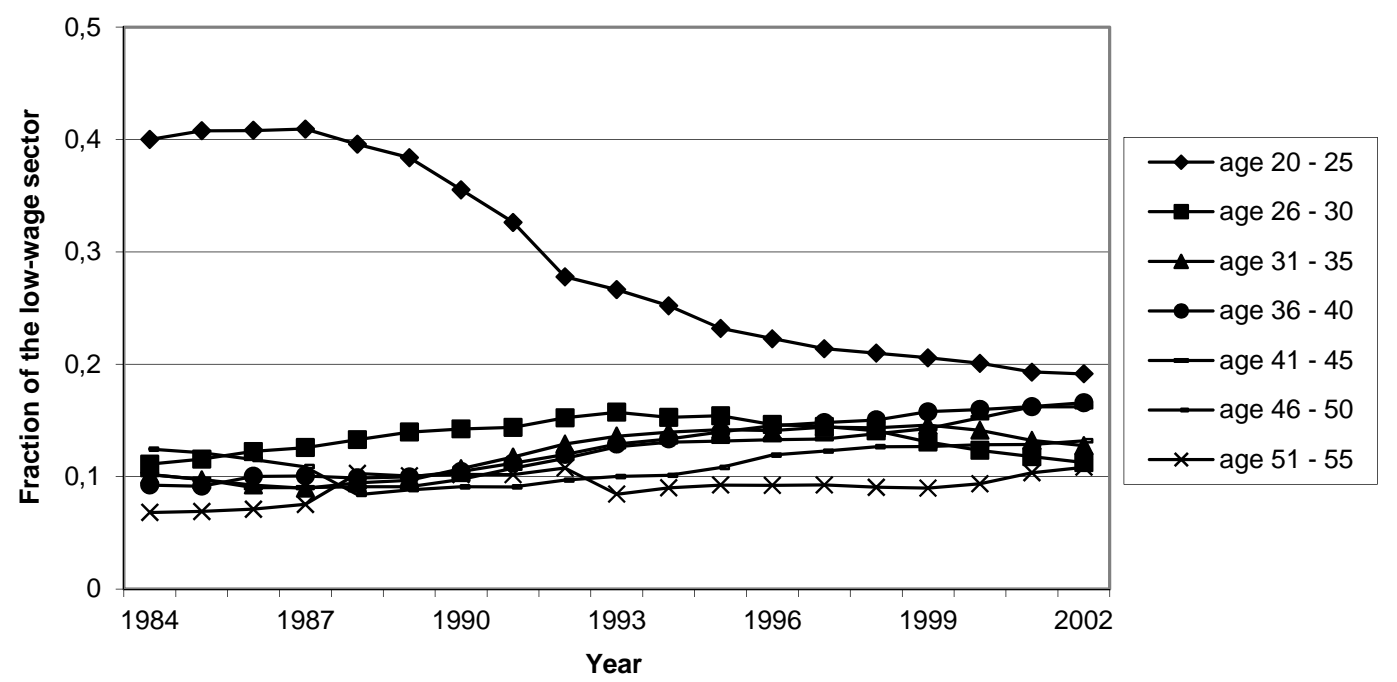

workers in the male high-wage population remained quite stable between 1984 and 1995 (9 to 10 per cent), this fraction more than doubled from 13 to 28 per cent in the male low-wage sector. This development, which - albeit to a somewhat lesser extent - is also observed for females, reflects the rise in migration flows especially into the low-wage sector after the fall of communism and the opening of the Iron Curtain (e.g., Bauer and Zimmermann 1999). By 2002, the share of foreigners among low paid male workers declined back to 20 per cent. As foreign workers faced a higher risk of remaining low paid at the beginning of the observation period, these developments may have fostered an increase in $A S D$ until the mid-nineties and a slight decrease afterwards. For an overview, Table B3 in the Appendix summarizes the development of the composition of the low-wage sector for males and females by selected characteristics for the years 1984 and 2002.

Taken together, the descriptions shown above provide clear evidence of an increasing degree of persistence in the low-wage sector. Moreover, the degree (and the evolution) of persistence varies considerably across observable attributes. It remains, however, unclear whether the increasing persistence can be fully attributed to a compositional shift towards more unfavorable observable characteristics. In addition to the observed developments fostering a rise in low-wage persistence, such as the increasing fraction of older workers and the less favorable skill composition among the low paid, a low-wage job per se might have increasingly caused low-wage employment in the future, regardless of the evolution 
of observable attributes. Such a development could stem from an increase in "true" or genuine state-dependence. The question of to what extent the observed increase in $A S D$ is accounted for by a less favorable composition of low-wage workers or an increase in genuine state dependence will therefore be addressed in the next section using a multivariate econometric framework.

\section{Econometric Analysis of Low-Pay Transitions}

To explore the extent to which the observed decline in the probability of escaping low earnings reflects an increase in genuine state dependence, we characterize the determinants of low-pay persistence and exit rates by explicitly distinguishing between observed and unobserved heterogeneity and true state dependence.

\subsection{Model specification}

To analyze low-pay transitions for each year in our sample period, we estimate the probability of being low paid in period $t$, conditional on the lagged pay status in $t-5$, with $t=1989-2004$. An endogeneity issue which is commonly referred to as the 'initial conditions problem' (Heckman 1981) arises if the starting point of the earnings process cannot be observed in the data and the unobservables affecting this process are correlated. A common solution is to specify an additional equation for the initial condition and to allow for a correlation between the error terms of the initial conditions and the transition equation. A second endogeneity issue arises since pay transitions are only observable for employees who stay full-time employed five years later. If unobservables affecting the probability of dropping out and the initial low-pay status are correlated, the resulting earnings attrition will be endogenous to the pay transition process. ${ }^{10}$

In order to account for these selection mechanisms, we estimate a series of trivariate probit models. Each model includes the determination of low-pay status in period $t-5$ (to account for the initial conditions problem), the determination of whether full-time

\footnotetext{
${ }^{10}$ Descriptive evidence from Table B2 already suggests that the likelihood of earnings retention is larger for high paid than for low paid workers.
} 
earnings are observed at both points in time, $t-5$ and $t$ (earnings retention), the determination of pay status in period $t$, and, finally, the correlation of unobservables affecting these processes. ${ }^{11}$

We first specify the initial low-pay status. Let $l_{i t-5}^{*}$ denote a latent low-pay propensity for individual $i$ at the start of the observation period and $x_{i t-5}$ represents a set of individual-specific characteristics. $x_{i t-5}$ includes seven different age groups, tenure, tenure squared, a dummy indicating foreign nationality as well as dummies on educational attainment (three categories) and occupational status to capture labor market experience and human capital endowment. We also include information on the previous employment history such as the employment status prior to entry into the current establishment, the number of previous unemployment and non-employment spells as well as the cumulated duration of previous unemployment and non-employment spells. We further control for the sectoral affiliation as well as regional dummies. $u_{i t-5}$ is the sum of an individualspecific effect, $\mu_{i}$, and an orthogonal white-noise error, $\delta_{i t-5}$, and is assumed to follow a standard normal distribution.

$$
l_{i t-5}^{*}=\beta^{\prime} x_{i t-5}+u_{i t-5}, \quad u_{i t-5} \sim N(0,1)
$$

If $l_{i t-5}^{*}$ exceeds some unobservable value (normalized to zero), individual $i$ is observed to be low paid. We define a binary indicator $L_{i t-5}=1$ if $l_{i t-5}^{*}>0$ and zero otherwise.

The next process to be specified is the earnings retention. We assume that the propensity to observe full-time earnings of individual $i$ in period $t-5$ and $t$ can be described by a latent retention index $r_{i t}^{*}$,

$$
r_{i t}^{*}=\delta^{\prime} y_{i t-5}+\varepsilon_{i t}, \quad \varepsilon_{i t} \sim N(0,1),
$$

\footnotetext{
${ }^{11}$ Due to computational constraints, we do not exploit the panel structure of our data as we estimate the trivariate model separately for each of the 16 years of our observation period. However, as our main focus is to analyze the evolution of $G S D$ over time in general, the individual correlations over time as well as the occurrence of lagged state dependence or feedback effects as investigated, e.g., by Biewen (2009) and Wooldridge (2005) are beyond the scope of this paper and might be subject to further research.
} 
where the error term $\varepsilon_{i t}$ is standard normally distributed and specified as the sum of an individual-specific effect, $\eta_{i}$, and an orthogonal white-noise error, $\xi_{i t-5} \cdot y_{i t-5}$ includes factors affecting both earnings and the attachment to paid employment. $y_{i t-5}$ contains $x_{i t-5}$, i.e. we assume that factors affecting earnings levels are generally also relevant in determining earnings retention. In order to identify the equation, we need to exclude one variable from $x_{i t-5}$ and add an additional one that affects the attachment to paid employment which is not part of $x_{i t-5}$ (see below). If the latent retention propensity of individual $i$ is lower than some critical unobserved value (again normalized to zero), earnings and low-pay status cannot be observed in period $t$. Let $R_{i t}$ be a binary variable of the earnings retention outcome of each individual, where $R_{i t}=1$ if $r_{i t}^{*}>0$ and zero otherwise.

The third component of the model is the specification of the low-pay status in period t. We assume that the latent propensity of low pay can be characterized by

$$
l_{i t}^{*}=\left[\left(L_{i t-5}\right) \gamma_{1}^{\prime}+\left(1-L_{i t-5}\right) \gamma_{2}^{\prime}\right] z_{i t-5}+v_{i t}, \quad v_{i t} \sim N(0,1)
$$

with $v_{i t}$ denoting the sum of an individual-specific effect, $\tau_{i}$, and an orthogonal white-noise error, $\zeta_{i t-5}$. The column vector $z_{i t-5}$ comprises individual-specific attributes affecting the pay status in $t$. In order to deal with simultaneous changes in covariates and pay status, the individual characteristics pertain to period $t-5$. The switching specification in (3) allows the impact of the explanatory variables to differ according to the low-pay status in the initial period. Again, $L_{i t}$ denotes a binary variable $L_{i t}=1$ if $l_{i t}^{*}>0$ and zero otherwise, where $L_{i t}$ is only observable if $R_{i t}=1$. As a consequence, the sample likelihood will be endogenously truncated.

We assume that the error terms in each of the three equations are jointly distributed as trivariate normal with unrestricted correlations, which can be written as

$$
\begin{aligned}
& \rho_{1} \equiv \operatorname{corr}\left(u_{i t-5}, \varepsilon_{i t}\right) \\
& \rho_{2} \equiv \operatorname{corr}\left(u_{i t-5}, v_{i t}\right) \\
& \rho_{3} \equiv \operatorname{corr}\left(v_{i t}, \varepsilon_{i t}\right) .
\end{aligned}
$$


The cross-equation correlations provide a parameterization of unobserved heterogeneity. The correlation $\rho_{1}$ describes the relationship between unobservable factors affecting the initial low-pay status and earnings retention. A negative sign suggests that individuals who were more likely to be low paid in the initial period are more likely to drop out of fulltime employment compared with high paid individuals. The correlation $\rho_{2}$ summarizes the association between unobservable factors determining the initial and the current low-pay status. Here, a positive sign would imply that individuals earning low pay in $t-5$ are more likely to remain in the low-pay status. The correlation $\rho_{3}$ characterizes the relationship between unobservables affecting the retention propensity and the current low-pay status. A negative sign would indicate that individuals employed at both points in time are more likely to escape low pay in $t$ as compared to individuals dropping out of full-time employment. Estimation of unconstrained cross-correlation coefficients provides a test of whether initial conditions and the earnings retention process may be treated as exogenous. In particular, $\rho_{1}=\rho_{3}=0$ would imply that the earnings retention process is exogenous and would give rise to a bivariate probit model. Similarly, testing the exogeneity of initial conditions amounts to testing $\rho_{1}=\rho_{2}=0$. Finally, if all cross-equation correlations are zero, then $\gamma_{1}$ and $\gamma_{2}$ can be consistently estimated using univariate probit models on subsamples depending on individuals' initial pay status $\left(L_{i t-5}=0\right.$ or $\left.L_{i t-5}=1\right)$.

Estimating the model with unrestricted cross-equation correlations requires identifying restrictions, i.e. variables entering $x_{i t-5}$ and $y_{i t-5}$ but not $z_{i t-5}$. In other words, one ideally needs variables that affect the initial condition and the retention probability but not the transition process. In what follows, we will argue that variables proxying the stability of a worker's employment history might satisfy these requirements. This is based upon the notion that low-wage jobs may be the result of asymmetric information about a worker's true productivity, which is not known ex-ante and becomes known more precisely as a worker's job tenure increases (Jovanovic 1979). In this case, the less regular the employment history, the more difficult it becomes for an individual to signal high productivity, which determines the initial wage. Once, however, an individual is observed five years later in the sample, the employment history may be expected to lose importance in determining an individual's wage position. Thus, employment history variables may be 
suitable instruments as they are likely to affect the attachment to full-time employment and the probability of being initially low paid, but not the low-pay transition. We will test the validity of our exclusion restrictions imposed for identification using functional form as the identifying restriction. As will be shown in Section 3.3.1., excluding the number of previous employers until 1989 (the number of previous unemployment spells after 1989) from the transition and retention equation as well as the number of employment interruptions with the current employer from the transition and initial conditions equation fulfills the requirements for the validity of these restrictions for the men's model. For women, we use the total unemployment duration as an identifying variable for the retention process as well as the number of employment interruptions with the current employer for the initial low-pay status and exclude these variables from the transition equation. ${ }^{12}$

\subsection{Measures of State Dependence}

To investigate the extent to which the decline in the probability of escaping low earnings is caused by an increase in the persistence of low-wage employment, we distinguish between aggregate state dependence $(A S D)$ and genuine state dependence $(G S D)$. ASD is obtained by computing the difference in average predicted transition probabilities for those who were low paid in $t-5$ and for those who were initially high paid:

$$
\begin{aligned}
A S D & =\frac{\sum_{i \in\left(L_{i t-5}=1, R_{i t}=1\right)} \operatorname{Pr}\left(L_{i t}=1 \mid L_{i t-5}=1\right)}{\sum_{i} L_{i t-5} \cdot R_{i t}}-\frac{\sum_{i \in\left(L_{i t-5}=0, R_{i t}=1\right)} \operatorname{Pr}\left(L_{i t}=1 \mid L_{i t-5}=0\right)}{\sum_{i}\left(1-L_{i t-5}\right) \cdot R_{i t}} \\
& =\frac{\sum_{i \in\left(L_{i t-5}=1, R_{i t}=1\right)} \frac{\Phi_{2}\left(z_{i t-5} \widehat{\gamma}_{1}, x_{i t-5} \widehat{\beta} ; \rho_{2}\right)}{\Phi\left(x_{i t-5} \widehat{\beta}\right)}}{\sum_{i} L_{i t-5} \cdot R_{i t}}-\frac{\sum_{i \in\left(L_{i t-5}=0, R_{i t}=1\right)} \frac{\Phi_{2}\left(z_{i t-5} \widehat{\gamma}_{2},-x_{i t-5} \widehat{\beta} ;-\rho_{2}\right)}{\Phi\left(-x_{i t-5} \widehat{\beta}\right)}}{\sum_{i}\left(1-L_{i t-5}\right) \cdot R_{i t}}, \quad(7)
\end{aligned}
$$

where $\Phi(\cdot)$ and $\Phi_{2}(\cdot)$ are cumulative density functions of the univariate and bivariate standard normal distributions. This measure does not take into account individual observed or unobserved heterogeneity.

\footnotetext{
${ }^{12}$ Although Jovanovic (1979) does not explicitly allow for recalls in his model, it is reasonable to assume that the number of employment interruptions may worsen the precision of workers' signals with respect to their true productivity.
} 
Genuine state dependence arises if initial low pay causes low-pay employment in the future for reasons of stigmatization or human capital depreciation. The absence of $G S D$ can be directly tested by using the endogenous switching structure in (3) and amounts to testing the null hypothesis $H_{0}: \gamma_{1}=\gamma_{2}$. To account for individual-specific heterogeneity, the $G S D$ is based upon individual-specific probability differences. In particular, $G S D$ is derived by first predicting for each individual with earnings retention five years later two transition probabilities, of which one will be counterfactual: i) the probability of staying in the low-wage sector (conditional on being initially low paid) and ii) the probability of entering the low-wage sector (conditional on being initially high paid). In a second step, the individual differences of these predicted transition probabilities are averaged over the sample of those with observed earnings in $t$ and $t-5$ :

$$
\begin{aligned}
G S D= & \frac{1}{\sum_{i} R_{i t}} \sum_{i \in R_{i t}=1}\left[\operatorname{Pr}\left(L_{i t}=1 \mid L_{i t-5}=1\right)-\operatorname{Pr}\left(L_{i t}=1 \mid L_{i t-5}=0\right)\right]= \\
& \frac{1}{\sum_{i} R_{i t}} \sum_{i \in R_{i t}=1}\left[\frac{\Phi_{2}\left(z_{i t-5} \widehat{\gamma}_{1}, x_{i t-5} \widehat{\beta} ; \rho_{2}\right)}{\Phi\left(x_{i t-5} \widehat{\beta}\right)}-\frac{\Phi_{2}\left(z_{i t-5} \widehat{\gamma}_{2},-x_{i t-5} \widehat{\beta} ;-\rho_{2}\right)}{\Phi\left(-x_{i t-5} \widehat{\beta}\right)}\right]
\end{aligned}
$$

The log-likelihood contribution for each individual $i$ with earnings information observed in period $t-5$ is:

$$
\begin{aligned}
\log £_{i}= & L_{i t-5} R_{i t} \log \left[\Phi_{3}\left(g_{i} \gamma_{1}^{\prime} z_{i t-5}, h_{i} \delta^{\prime} y_{i t-5}, d_{i} \beta^{\prime} x_{i t-5} ; g_{i} h_{i} \rho_{3}, g_{i} d_{i} \rho_{2}, h_{i} d_{i} \rho_{1}\right)\right] \\
& +\left(1-L_{i t-5}\right) R_{i t} \log \left[\Phi_{3}\left(g_{i} \gamma_{2}^{\prime} z_{i t-5}, h_{i} \delta^{\prime} y_{i t-5}, d_{i} \beta^{\prime} x_{i t-5} ; g_{i} h_{i} \rho_{3}, g_{i} d_{i} \rho_{2}, h_{i} d_{i} \rho_{1}\right)\right] \\
& +\left(1-R_{i t}\right) \log \left[\Phi_{2}\left(h_{i} \delta^{\prime} y_{i t-5}, d_{i} \beta^{\prime} x_{i t-5} ; h_{i} d_{i} \rho_{1}\right)\right]
\end{aligned}
$$

where $\Phi_{3}$ is the cumulative density function of the trivariate standard normal distribution and $g_{i} \equiv 2 L_{i t}-1, h_{i} \equiv 2 R_{i t}-1, d_{i} \equiv 2 L_{i t-5}-1$. We compute the trivariate standard normal distribution by applying the Geweke-Hajivassiliou-Keane (GHK) simulator, yielding a maximum simulated likelihood (MSL) estimator (see Cappellari and Jenkins 2003 and 2006). 


\section{$3.3 \quad$ Results}

\subsubsection{Correlation structure and hypothesis tests}

For each year, our estimation sample is based on those individuals for whom we observe full-time earnings in our data set. That the trivariate probit model is necessary to derive consistent estimates of our parameters of interest is confirmed for all years as the hypothesis that $\rho_{1}=\rho_{3}$ and $\rho_{1}=\rho_{2}$ has to be clearly rejected at the 0.1 per cent significance level for both men and women. This provides evidence of the endogeneity of the initialconditions process and the earnings retention process. The tests also show for men as well as for women that the hypothesis $\gamma_{1}=\gamma_{2}$ and, thus, the hypothesis of no genuine state dependence must be rejected at the 0.1 per cent significance level in each of the 16 years of our observation period.

The cross equation correlation structure is summarized in Table 1 for both male and female workers. As expected, the correlation between unobservables affecting retention and initial conditions is estimated to be negative, indicating that those who were initially

Table 1: Equation correlation structure

\begin{tabular}{lllllll}
\hline Year & \multicolumn{3}{c}{ Males } & \multicolumn{3}{c}{ Females } \\
& $\rho_{1}$ & $\rho_{2}$ & \multicolumn{1}{c}{$\rho_{3}$} & $\rho_{1}$ & $\rho_{2}$ & \multicolumn{1}{c}{$\rho_{3}$} \\
\hline 1984 & $-.223^{* * *}$ & 0.008 & $0.272^{* *}$ & $-.157^{* * *}$ & 0.607 & 0.213 \\
1985 & $-.202^{* * *}$ & 0.054 & $0.406^{* * *}$ & $-.131^{* * *}$ & 0.082 & $0.477^{* *}$ \\
1986 & $-.176^{* * *}$ & -.200 & $0.348^{* * *}$ & $-.132^{* * *}$ & $0.285^{*}$ & $0.412^{* *}$ \\
1987 & $-.206^{* * *}$ & -.183 & 0.140 & $-.115^{* * *}$ & 0.200 & $0.409^{*}$ \\
1988 & $-.207^{* * *}$ & -.299 & 0.131 & $-.118^{* * *}$ & 0.078 & $0.544^{* * *}$ \\
1989 & $-.198^{* * *}$ & -.046 & $0.298^{* *}$ & $-.113^{* * *}$ & 0.114 & $0.459^{* * *}$ \\
1990 & $-.199^{* * *}$ & $-.368^{*}$ & $0.199^{*}$ & $-.117^{* * *}$ & 0.227 & $0.436^{* * *}$ \\
1991 & $-.210^{* * *}$ & -.206 & -.070 & $-.132^{* * *}$ & 0.183 & $0.394^{* *}$ \\
1992 & $-.218^{* * *}$ & -.261 & 0.009 & $-.132^{* * *}$ & 0.148 & $-.194^{* *}$ \\
1993 & $-.240^{* * *}$ & -.229 & 0.279 & $-.142^{* * *}$ & $-.902^{* * *}$ & 0.003 \\
1994 & $-.214^{* * *}$ & -.061 & $-.205^{* *}$ & $-.145^{* * *}$ & -.127 & $-.239^{* * *}$ \\
1995 & $-.223^{* * *}$ & 0.099 & $-.176^{* *}$ & $-.150^{* * *}$ & 0.108 & $-.279^{* * *}$ \\
1996 & $-.235^{* * *}$ & $-.351^{*}$ & $-.297^{* * *}$ & $-.154^{* * *}$ & -.103 & -.048 \\
1997 & $-.221^{* * *}$ & -.098 & $-.171^{* *}$ & $-.150^{* * *}$ & 0.053 & -.146 \\
1998 & $-.225^{* * *}$ & -.356 & -.056 & $-.144^{* * *}$ & 0.176 & $-.209^{* *}$ \\
1999 & $-.234^{* * *}$ & -.204 & $-.255^{* * *}$ & $-.160^{* * *}$ & -.275 & -.181 \\
\hline Note: $\rho_{1}$ : Correlation between initial conditions and retention; & \\
$\rho_{2}:$ Correlation between initial conditions and low-pay transition; & \\
$\rho_{3}:$ Correlation between retention and low-pay transition; & \\
Significance levels: ***: p<0.01;**:p<0.05; *: p<0.1. & &
\end{tabular}


low paid are less likely to be employed at both points in time. A significant correlation between the initial condition and the transition equation cannot be found, neither for male nor for female workers. This suggests that any bias due to the selection into low-wage employment influences the transition process through its impact on employer retention. Interestingly, the correlation between the retention and the transition equation has changed over time for men as well as for women. In the first years of our observation period, we observe a significantly positive relationship between unobservables affecting the retention propensity and low-pay persistence. This indicates that individuals employed at both points in time were less likely to escape low pay in $t$ as compared to individuals dropping out of full-time employment. In the mid 1990s, the sign switches for both sexes and becomes significant in some years. Note that a potential explanation for this finding may relate to the change in the age composition of the low-wage sector. Figures 6 and 7 reveal that the start of the deceleration in the decline in the young workers' share roughly coincides with the estimated switch in the correlation between retention and low-pay persistence. Given that low-pay is more likely to reflect entry wages in the first half of our observation period, this may help explain the positive association between unobservables favoring low-pay persistence as well as employment stability. In the second half of our observation period, in contrast, low-pay workers appear to be more negatively selected upon unobservables fostering persistence as well as instable employment histories.

To be validly identified, the typical identifying conditions need to hold for each of the trivariate models, i.e. the excluded variables should have a significant impact on retention (the initial condition) but not on the low-pay transition. Thus, in our case the conditions require the number of employment interruptions with the current employer to significantly affect the men's probability of staying in the sample in a given year but, at the same time, to have no significant impact on the probability of staying in the low-wage sector. As can be seen from Table 2, the two excluded variables have a significant impact on the retention and the initial conditions equation for male workers in each of the 16 years. For women, we similarly observe a significant effect of the number of employment interruptions with the current employer on the probability of initially earning a low wage for all years. The effect of the total unemployment duration on the retention probability 
Table 2: Inclusion of instruments

\begin{tabular}{lcccc}
\hline \multirow{2}{*}{ Year } & \multicolumn{2}{c}{ Males } & \multicolumn{2}{c}{ Females } \\
& $\begin{array}{c}\text { Instr. 1 in } \\
\text { retention eq. }\end{array}$ & $\begin{array}{c}\text { Instr. 2 in } \\
\text { init. cond. eq. }\end{array}$ & $\begin{array}{c}\text { Instr. 1 in } \\
\text { retention eq. }\end{array}$ & $\begin{array}{c}\text { Instr. 2 in } \\
\text { init. cond. eq. }\end{array}$ \\
\hline 1984 & 0.000 & 0.000 & 0.029 & 0.000 \\
1985 & 0.004 & 0.000 & 0.059 & 0.000 \\
1986 & 0.001 & 0.000 & 0.652 & 0.000 \\
1987 & 0.003 & 0.000 & 0.463 & 0.000 \\
1988 & 0.000 & 0.000 & 0.132 & 0.000 \\
1989 & 0.000 & 0.000 & 0.460 & 0.000 \\
1990 & 0.000 & 0.000 & 0.006 & 0.000 \\
1991 & 0.000 & 0.000 & 0.024 & 0.000 \\
1992 & 0.000 & 0.000 & 0.008 & 0.000 \\
1993 & 0.000 & 0.000 & 0.017 & 0.000 \\
1994 & 0.001 & 0.000 & 0.172 & 0.000 \\
1995 & 0.006 & 0.000 & 0.382 & 0.000 \\
1996 & 0.000 & 0.000 & 0.401 & 0.000 \\
1997 & 0.001 & 0.000 & 0.369 & 0.000 \\
1998 & 0.023 & 0.000 & 0.013 & 0.000 \\
1999 & 0.008 & 0.000 & 0.000 & 0.000 \\
\hline
\end{tabular}

Note: All values are $p$-values. For men, instrument 1 denotes the number of employment interruptions with the current employer; instrument 2 denotes the number of previous employers until 1989; after 1989 instrument 2 refers to the number of previous unemployment spells. For females, instrument 1 denotes the total unemployment duration; instrument 2 is the number of employment interruptions with the current employer.

is, however, only significant in 8 out of the 16 years.

An overview of the tests concerning the second condition - the insignificant impact of the excluded variables in the transition equation - is given in Table 3 for both men and women. While the first two columns show for each sex the significance tests for each excluded variable separately, the third column displays the joint significance test of the two excluded variables in the transition equation. We observe for male workers that the number of previous employers (until 1989) and the number of previous unemployment spells (since 1990) seem to be valid instruments for the initial conditions equation. With the exception of 1987, the impact of these variables on the likelihood to stay in the low-wage sector is insignificant at the 5 per cent level. The number of employment interruptions also turns out to be a suitable exclusion restriction as the variable has no significant impact in the transition equation in the majority of years. As a result, the joint significance test accepts the hypothesis (at the 5 per cent significance level) of the two variables having no impact in the transition equation in 12 out of 16 years. 
The tests of the insignificance of the excluded variables for women reveal that both variables seem to provide valid exclusion restrictions for the majority of years. This is shown by the joint significance test that accepts the hypothesis (at the 5 per cent significance level) that the two variables have no impact in the transition equation for 11 out of 16 years. However, for both excluded variables there are some periods where the requirements for a valid identification are not fully met. While the total unemployment duration has a significant impact in the transition equation in the last three years of our observation period (1997-1999), the number of employment interruptions with the current employer affects the likelihood of staying in the low-wage sector significantly between 1987 and 1991. Since - as seen in Table 2 - the impact of this variable on the initial conditions equation is at the same time not significant, a valid identification of the women's model might not be achieved for some years in the late 1980s, so that the results for these years should be interpreted with caution. Taken together, however, the tests show that for the majority of years, the trivariate probit models are well identified for both men and women.

Table 3: Exclusion of instruments from the transition equation

\begin{tabular}{ccccccc}
\hline Year & \multicolumn{3}{c}{ Males } & \multicolumn{3}{c}{ Females } \\
& Instr. 1 & Instr. 2 & Instr. 1+2 & Instr. 1 & Instr. 2 & Instr. 1+2 \\
\hline 1984 & 0.159 & 0.328 & 0.181 & 0.488 & 0.611 & 0.659 \\
1985 & 0.026 & 0.316 & 0.092 & 0.838 & 0.724 & 0.908 \\
1986 & 0.382 & 0.495 & 0.506 & 0.604 & 0.444 & 0.619 \\
1987 & 0.024 & 0.021 & 0.001 & 0.994 & 0.008 & 0.047 \\
1988 & 0.333 & 0.376 & 0.271 & 0.498 & 0.030 & 0.076 \\
1989 & 0.008 & 0.388 & 0.013 & 0.715 & 0.001 & 0.004 \\
1990 & 0.268 & 0.301 & 0.245 & 0.818 & 0.000 & 0.001 \\
1991 & 0.042 & 0.156 & 0.031 & 0.702 & 0.001 & 0.004 \\
1992 & 0.007 & 0.742 & 0.031 & 0.467 & 0.570 & 0.607 \\
1993 & 0.388 & 0.435 & 0.432 & 0.849 & 0.256 & 0.565 \\
1994 & 0.576 & 0.213 & 0.430 & 0.342 & 0.975 & 0.696 \\
1995 & 0.071 & 0.314 & 0.103 & 0.301 & 0.244 & 0.251 \\
1996 & 0.443 & 0.751 & 0.690 & 0.142 & 0.427 & 0.214 \\
1997 & 0.069 & 0.312 & 0.119 & 0.027 & 0.603 & 0.077 \\
1998 & 0.037 & 0.442 & 0.086 & 0.007 & 0.961 & 0.042 \\
1999 & 0.898 & 0.252 & 0.562 & 0.074 & 0.189 & 0.063 \\
\hline
\end{tabular}

Note: All values are $p$-values. For men, instrument 1 denotes the number of employment interruptions with the current employer, instrument 2 denotes the number of previous employers until 1989; after 1989 instrument 2 refers to the number of previous unemployment spells. For women, instrument 1 denotes the total unemployment duration, instrument 2 is the number of employment interruptions with the current employer. 


\subsubsection{Regression results}

After having clarified the conditions for identification, we summarize the estimation results over all 16 years for male workers in Table 4 and for female workers in Table 5 . The table shows for all variables their impact on the retention probability $\left(R_{t}\right)$, the initial conditions $\left(L_{t-5}\right)$, the likelihood of entering the low-wage sector conditional on being initially high paid $\left(L_{t} \mid L_{t-5}=0\right)$ and the likelihood of staying in the low-wage sector conditional on being initially low paid $\left(L_{t} \mid L_{t-5}=1\right)$. We summarize the estimation results for each equation by two different indicators. To get an impression of each variable's robustness over time, the first column not only displays for each equation the direction of the sign, which is most often observed over time, but also measures the frequency of the signs' appearance of the estimated coefficients on a scale of one $(+/-)$ to three $(+++/---)$, with $+++/---$ representing a positive/negative effect in each of the 16 years. The second column provides insights into each covariate's consistency over time by summing up the number of years in which the sign of the estimated coefficient switched.

The variables explain the dependent variables over time quite robustly as the estimated coefficients do not change their sign over time for the majority of the covariates. If they do so, they most likely change it only once, indicating a possible structural change in the variables' influence on the different processes. This result applies to men as well as to women, although the estimation results for men seem to show a somewhat higher degree of robustness in terms of both indicators.

Turning first to the earnings retention and the initial conditions process, a comparison of the equations reveals that for male workers almost all covariates exhibit opposite signs with respect to their impact on both processes (see Table 4). Characteristics that reflect unstable employment records like longer un- and non-employment durations, a higher

number of non-employment spells as well as employment interruptions and a change of the employer, favor the likelihood of being initially low paid and reduce the probability of remaining full-time employed five years later. Also, being foreign makes it more likely to be initially low paid and decreases the retention probability. For other variables, the interpretation works just the other way around: not surprisingly, a higher tenure as well 
Table 4: Regression summary for men, 1984 - 1999

\begin{tabular}{|c|c|c|c|c|c|c|c|c|}
\hline \multirow[t]{2}{*}{ Variables } & \multicolumn{2}{|c|}{$R_{t}$} & \multicolumn{2}{|c|}{$L_{t-5}$} & \multicolumn{2}{|c|}{$L_{t} \mid L_{t-5}=0$} & \multicolumn{2}{|c|}{$L_{t} \mid L_{t-5}=1$} \\
\hline & 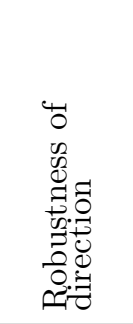 & 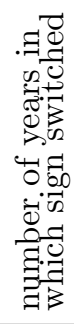 & 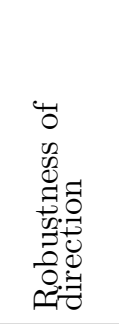 & 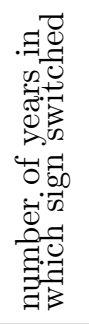 & 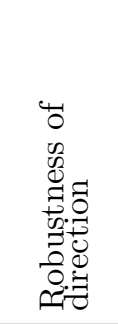 & 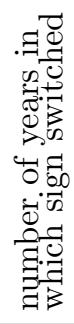 & 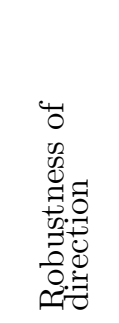 & 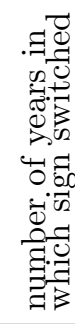 \\
\hline Age $26-30$ (ref.: age $20-25)$ & $+++^{1}$ & 0 & --- & 0 & --- & 0 & +++ & 0 \\
\hline Age $31-35$ & +++ & 0 & --- & 0 & --- & 0 & +++ & 0 \\
\hline Age $36-40$ & ++ & 1 & --- & 0 & --- & 0 & +++ & 0 \\
\hline Age $41-45$ & ++ & 1 & --- & 0 & --- & 0 & +++ & 0 \\
\hline Age $46-50$ & -- & 1 & --- & 0 & -- & 2 & +++ & 0 \\
\hline Age $51-55$ & --- & 0 & --- & 0 & - & 0 & +++ & 0 \\
\hline Tenure & +++ & 0 & --- & 0 & --- & 0 & +++ & 0 \\
\hline Tenure squared & --- & 0 & ++ & 1 & ++ & 1 & -- & 3 \\
\hline Being foreign $(=1)$ & --- & 0 & +++ & 0 & +++ & 0 & ++ & 4 \\
\hline Medium-skilled (ref.: low-skilled) & +++ & 0 & --- & 0 & --- & 0 & --- & 0 \\
\hline High-skilled & +++ & 0 & --- & 0 & --- & 0 & --- & 0 \\
\hline Previously full-time empl. $(=1)$ & +++ & 0 & +++ & 0 & --- & 0 & + & 6 \\
\hline Total non-employment duration & --- & 0 & +++ & 0 & +++ & 0 & +++ & 0 \\
\hline Total unemployment duration & --- & 0 & +++ & 0 & +++ & 0 & +++ & 0 \\
\hline Number of non-empl. spells & --- & 0 & +++ & 0 & +++ & 0 & ++ & 3 \\
\hline Employment interruption $(=1)$ & --- & 0 & + & 7 & + & 7 & ++ & 2 \\
\hline Change of employer $(=1)$ & -- & 1 & +++ & 0 & +++ & 0 & -- & 4 \\
\hline Blue-collar worker $(=1)$ & +++ & 0 & +++ & 0 & +++ & 0 & +++ & 0 \\
\hline Number of unemployment spells ${ }^{2}$ & +++ & 0 & --- & 0 & --- & 0 & --- & 0 \\
\hline Number of previous employers ${ }^{3}$ & --- & 0 & --- & 0 & +++ & 0 & + & 3 \\
\hline Number of empl. interruptions & +++ & 0 & & & & & & \\
\hline
\end{tabular}

1) Measure of direction robustness:

$+++/---$ : Variable has a positive/negative impact in all 16 years.

$++/--$ : Variable has a positive/negative impact in 12 to 15 of the 16 years.

$+/-$ : Variable has a positive/negative impact in 9 to 11 of the 16 years.

2) Coefficients for $R_{t}$ and $L_{t} \mid L_{t-5}$ are only available for the years 1984-1989.

3) Coefficients for $R_{t}$ and $L_{t} \mid L_{t-5}$ are only available for the years 1990-1999.

as a higher education reduce the probability of an initial low-wage status and increase the retention probability. Only for blue-collar workers as well as for previous full-time employed individuals, we observe that the signs of the two coefficients point into the same direction. The retention probability as well as the probability of being initially low paid is higher for blue-collar (than for white-collar) workers and for those individuals who were previously full-time (rather than not full-time) employed. At first glance, the positive association between a previous full-time employment status and the probability of being 
initially low paid appears to be somewhat counterintuitive. However, this result may reflect the fact that males exhibiting non-standard employment relationships reflect a particularly selected group in the labor market. Considering age, we observe that workers below the age of 26 years face the highest risk of being low paid, whereas we see a Ushaped pattern with respect to the retention probability. Young workers (20 - 25 years) and older workers above 45 years face a lower retention probability than the middle-aged.

All in all, the signs of the variables vary little for female workers in comparison to men (see Table 5). Exceptions are skill and occupational status. Other than for men, being high-skilled (versus low-skilled) and being a blue-collar (versus a white-collar) worker reduces the retention probability. The estimation results demonstrate that especially females between 26 and 30 years have a lower probability of staying in the sample five years later compared to young female workers below 26 years. This result might be explained by the fact that women leave the labor market more frequently during that period, for example due to maternity leave. With respect to the initial condition process, a main difference between men and women concerns the previous employment status. In line with what one would expect, a previous full-time employed position now decreases the probability of being initially low paid.

Turning next to the transition equation, the coefficients of all covariates are allowed to differ - in line with our switching regression specification - across those who were initially low paid $\left(L_{t} \mid L_{t-5}=1\right)$ and for those initially high paid $\left(L_{t} \mid L_{t-5}=0\right)$. As one might expect, for most variables the signs of the estimated coefficient point into the same direction as in the initial conditions equation, particularly for those initially high paid. With respect to age, however, we see deviations conditional on the initial low-pay status for male as well as for female workers. Conditional on being initially high paid, younger individuals up to an age of 35 years have a higher probability than those older than 35 years to enter the low-wage sector five years later. In contrast, conditional on being initially low paid, the group of the youngest workers exhibits the lowest probability of sticking to a low-wage job. Thus, once earning a low wage, it is much more difficult for older individuals to escape from it than for the younger ones. This result is valid for 
Table 5: Regression summary for women, $1984-1999$

\begin{tabular}{|c|c|c|c|c|c|c|c|c|}
\hline \multirow[t]{2}{*}{ Variables } & \multicolumn{2}{|c|}{$R_{t}$} & \multicolumn{2}{|c|}{$L_{t-5}$} & \multicolumn{2}{|c|}{$L_{t} \mid L_{t-5}=0$} & \multicolumn{2}{|c|}{$L_{t} \mid L_{t-5}=1$} \\
\hline & 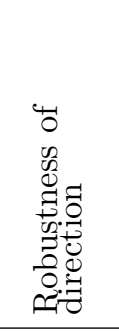 & 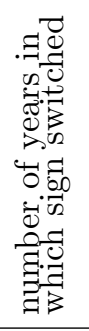 & 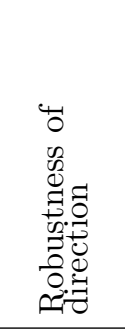 & 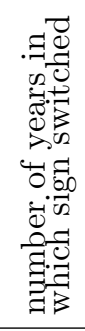 & 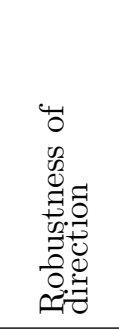 & 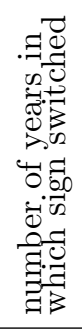 & 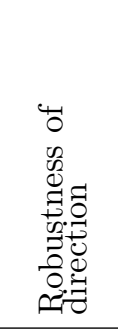 & 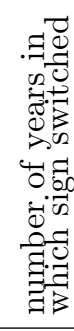 \\
\hline Age 26 - 30 (ref.: age $20-25$ ) & $--1)$ & 1 & --- & 0 & ++ & 4 & +++ & 0 \\
\hline Age $31-35$ & +++ & 0 & -- & 2 & + & 3 & +++ & 0 \\
\hline Age $36-40$ & +++ & 0 & -- & 4 & --- & 0 & +++ & 0 \\
\hline Age $41-45$ & +++ & 0 & --- & 0 & -- & 2 & +++ & 0 \\
\hline Age $46-50$ & +++ & 0 & -- & 2 & -- & 2 & +++ & 0 \\
\hline Age $51-55$ & - & 2 & - & 2 & -- & 3 & +++ & 0 \\
\hline Tenure & +++ & 0 & --- & 0 & -- & 2 & +++ & 0 \\
\hline Tenure squared & -- & 2 & ++ & 1 & ++ & 3 & --- & 0 \\
\hline Being foreign $(=1)$ & --- & 0 & - & 0 & -- & 4 & -- & 2 \\
\hline Medium-skilled (ref. low-skilled) & +++ & 0 & --- & 0 & o & 1 & -- & 2 \\
\hline High-skilled & - & 1 & --- & 0 & --- & 0 & --- & 0 \\
\hline Previously full-time empl. $(=1)$ & +++ & 0 & --- & 0 & --- & 0 & - & 4 \\
\hline Total non-employment duration & --- & 0 & +++ & 0 & +++ & 0 & +++ & 0 \\
\hline Number of non-empl. spells & --- & 0 & +++ & 0 & ++ & 2 & - & 6 \\
\hline Number of previous employers & --- & 0 & --- & 0 & + & 1 & -- & 5 \\
\hline Employment interruption $(=1)$ & --- & 0 & +++ & 0 & ++ & 4 & ++ & 1 \\
\hline Change of employer $(=1)$ & -- & 3 & +++ & 0 & ++ & 2 & + & 4 \\
\hline Number of unemployment spells & + & 4 & ++ & 1 & +++ & 0 & ++ & 6 \\
\hline Blue-collar worker $(=1)$ & --- & 0 & +++ & 0 & +++ & 0 & +++ & 0 \\
\hline Total unemployment duration & -- & 2 & & & & & & \\
\hline Number of empl. interruptions & & & --- & 0 & & & & \\
\hline
\end{tabular}

1) Measure of direction robustness:

$+++/---$ : Variable has a positive/negative impact in all 16 years.

$++/--$ : Variable has a positive/negative impact in 12 to 15 of the 16 years.

$+/-$ : Variable has a positive/negative impact in 9 to 11 of the 16 years.

o: Variable has a positive and a negative impact in 8 of the 16 years.

both men and women and confirms the descriptive findings from Section 2.3.

To assess the quantitative meaning of a variable's impact, it is necessary to derive the marginal effects as is described in Appendix C. Table 6 exemplarily displays the marginal effects of the explanatory variables on the low-pay transition probabilities for male workers in 1999. In line with the switching regression specification, the effects are reported separately for those who were initially low paid and for those initially high paid. For the former group, the effects are to be interpreted in terms of persistence effects, whereas for the latter group the marginal effects refer to the probability of entering low pay. Marginal effects are to be interpreted as deviations from a reference person who has 
all dummies set to zero and is defined by setting the continuous covariates equal to their sample median values. ${ }^{13}$

Table 6: Marginal effects for male workers in 1999

\begin{tabular}{|c|c|c|c|c|}
\hline & \multicolumn{2}{|c|}{$L_{t} \mid L_{t-5}=1$} & \multicolumn{2}{|c|}{$L_{t} \mid L_{t-5}=0$} \\
\hline & $\mathrm{ME}$ & Std. error & $\mathrm{ME}$ & Std. error \\
\hline Average prediction & \multicolumn{2}{|c|}{0.476} & \multicolumn{2}{|c|}{0.022} \\
\hline Baseline & \multicolumn{2}{|c|}{0.589} & \multicolumn{2}{|c|}{0.022} \\
\hline Tenure & 0.000 & 0.572 & -.000 & 3.476 \\
\hline Tenure squared & -.000 & 0.001 & 0.000 & 0.004 \\
\hline Total non-employment duration & 0.000 & 0.072 & 0.000 & 0.841 \\
\hline Total unemployment duration & 0.000 & 0.092 & 0.000 & 5.608 \\
\hline Number of non-employment spells & -.004 & 19.967 & 0.003 & 754.08 \\
\hline Number of previous employers & 0.008 & 39.628 & 0.001 & 188.82 \\
\hline Age $26-30$ & $0.063^{* * *}$ & 0.000 & $-.009^{* * *}$ & 0.000 \\
\hline Age $31-35$ & $0.099^{* * *}$ & 0.001 & $-.010^{* * *}$ & 0.000 \\
\hline Age $36-40$ & $0.121^{* * *}$ & 0.001 & $-.011^{* * *}$ & 0.002 \\
\hline Age $41-45$ & $0.172^{* * *}$ & 0.003 & $-.011^{* * *}$ & 0.000 \\
\hline Age $46-50$ & $0.185^{* * *}$ & 0.003 & $-.008 * * *$ & 0.002 \\
\hline Age $51-55$ & $0.231^{* * *}$ & 0.002 & -.004 & 0.003 \\
\hline Being foreign & 0.000 & 0.008 & 0.009 & 0.005 \\
\hline Medium-skilled & $-.049 * * *$ & 0.009 & $-.008^{* *}$ & 0.003 \\
\hline High-skilled & $-.140 * * *$ & 0.011 & $-.021 * * *$ & 0.001 \\
\hline Previously full-time employed & $0.018^{* * *}$ & 0.005 & $-.012^{* *}$ & 0.004 \\
\hline Employment interruption $(=1)$ & $0.020 * * *$ & 0.005 & -.001 & 0.003 \\
\hline Change of employer $(=1)$ & 0.005 & 0.012 & 0.005 & 0.003 \\
\hline Blue-collar worker $(=1)$ & $0.012^{*}$ & 0.005 & $-.041^{*}$ & 0.016 \\
\hline $\mathrm{N}$ (Individuals) & \multicolumn{2}{|c|}{14,549} & \multicolumn{2}{|c|}{175,771} \\
\hline
\end{tabular}

The first two rows in Table 6 report the average transition probabilities - which represent the two components of the $A S D$ derived in equation (7) - as well as the transition probabilities for the reference individual - which are referred to as the baseline probabilities. The baseline persistence probability of 0.589 is considerably larger than the average transition probability, whereas no difference is observed for entry probabilities. The ME estimates indicate that observable individual attributes significantly affect the probability of both staying and becoming low paid. While a better education reduces the probabil-

\footnotetext{
${ }^{13}$ A reference individual is a German between the age of 20 to 25 years who has a vocational degree, a white-collar occupation and has had no regular employment relationship and three previous employers prior to entry into the current establishment. Moreover, the reference worker has a median tenure of 2,040 days, has been non-employed for 90 days and has not yet been unemployed.
} 
ity of both staying and becoming low paid, other variables have opposite effects on the low-wage persistence and entry probabilities. The marginal effects confirm earlier results from Table 4, which suggest that the likelihood of entering the low-wage sector is highest for the youngest workers below 26 years, whereas the likelihood of remaining low paid is the lowest for this subgroup. An individual who is between 41 and 45 years, for example, has a persistence (entry) probability which is 17.2 (1.1) percentage points higher (lower) than that of an individual aged between 20 and 25 years, ceteris paribus. The continuous employment history variables like tenure and total unemployment duration do not have any explanatory power.

Overall, the estimation results indicate that for both males and females age rather than the employment history variables drive the persistence probability. For example, whether an individual has a long or a short record of days in unemployment is not of major importance once an individual earns a low wage. This suggests that the extent of true state dependence is quite substantial.

\subsubsection{The evolution of genuine state dependence $(G S D)$}

After having estimated the transition equations, we next turn to the evolution of genuine state dependence $(G S D)$ as given by equation (8). In Figure 8, we plot the estimated aggregate state dependence $(A S D)$ and genuine state dependence $(G S D)$ against time, separately for men and women. The estimated $A S D$ values are nearly equal to the descriptive values that we showed earlier in Figure 3. Comparing the evolution of GSD and $A S D$, Figure 8 demonstrates that both measures are characterized by a quite divergent development. While the male $A S D$ has steadily risen over time from 25 per cent in 1987 to 45 per cent in 2002 , the GSD measure exhibits a stationary pattern by fluctuating at a rate around 40 per cent over the whole observation period. Thus, once observable characteristics are controlled for, our findings argue against an upward trend in genuine state dependence for the overall male workforce. For women, in contrast, there seems to have been a slight increase in GSD between 1990 and 1999 from 47 to 56 per cent. However,

the growth of $G S D$ has been distinctly lower than that of $A S D$ which rose from 46 to 65 per cent between 1987 and 2002. This result highlights the importance of accounting for 
changes in the composition of the low-wage relative to the high-wage labor work force and makes clear that the omission of such changing trends might lead to wrong inferences.

Figure 8: Evolution of aggregate (ASD) and genuine state dependence (GSD)

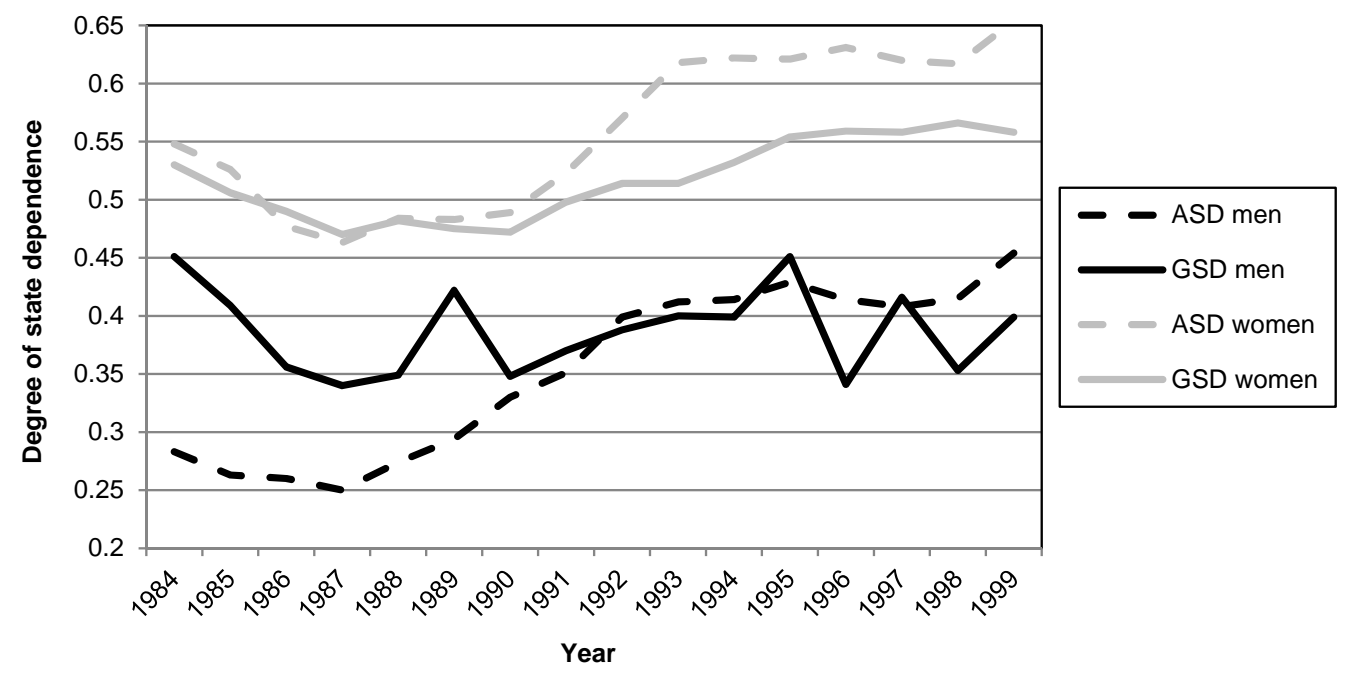

An important pattern that emerges from Figure 8 is that, especially for male workers, the extent of $G S D$ has been substantially higher than the $A S D$ during the first part of the observation period until 1991. This contrasts with earlier results from other studies (e.g., Cappellari and Jenkins 2004 and Cappellari 2007). Recall, however, that in our GSD measure we contrast for each individual - given his or her observed characteristics - the probability of entering the low-wage sector conditional on being initially high paid with the respective probability conditional on being initially low paid. One would typically expect that individuals working in the high-wage sector exhibit observed attributes that shelter them from low-wage persistence, even evaluated at the counterfactual persistence probability. However, our strong results with respect to the age structure's impact on transition probabilities lead to the opposite pattern. As individuals from the high-wage sector are on average four years older than those in the low-wage sector, their counterfactual persistence probabilities are considerably higher than their respective entry probabilities. This gives rise to a large $G S D$ value, which even exceeds the (observed) $A S D$ especially in the first years of our observation period when the difference in the average age between 
low and high-wage earners was considerably larger than in later years. ${ }^{14}$

We next turn to the evolution of GSD separately for the low-wage and high-wage sector. Figure 9 reveals that the level of $G S D$ differed substantially across low and high paid workers during the 1980s, especially for men. In other words, had a high paid male worker earned a low wage, his probability of staying in the low-wage sector would have been about 20 percentage points higher than for an actual low paid worker. During the end of the 1980s, the GSD of high and low paid workers converged for both sexes mainly because the $G S D$ of low paid workers increased more sharply. Note that this reflects the compositional shift of the low-wage relative to the high-wage sector that was already established in Figure 8. Since 1992, the evolution of $G S D$ among low paid women has been very similar to that for high paid women, whereas male low paid workers in 1999 still faced a lower $G S D$ level than their high paid counterparts.

Overall, Figure 9 demonstrates that there has actually been an increase in $G S D$ for male (as well as female) low paid workers. Thus, the evolution of $G S D$ for the overall male workforce as shown in Figure 8 masked substantial heterogeneity across low and high paid workers, as the majority of male workers earns a wage above the low-wage threshold. Comparing the evolution of $G S D$ among low-wage workers with the evolution of $A S D$, we see, however, that the increase in $A S D$ cannot fully be accounted for by the increase in $G S D$ among the low paid. The $G S D / A S D$ ratio decreases from 0.90 in 1984 to 0.78 in 1999 for male low paid workers while it ranges quite stationarily between 0.84 and 0.94 over the observation period for low paid women.

A closer look at the evolution of $G S D$ reveals that the increase during the 1990s for both high and low paid workers was preceded by a decline in the mid 1980s. We, thus, observe some cyclical pattern which differs across men and women only at the end of the observation period. One possible explanation for this pattern could relate to the evolution of the unemployment rate as a proxy for business cycle effects. It is commonly suggested in the literature that wages are procyclical, i.e wages grow more rapidly during

\footnotetext{
${ }^{14}$ While male (female) high-wage earners were on average $10(5)$ years older than low-wage earners in 1984, this difference dropped to 4 (1) years in 2002.
} 
Figure 9: GSD by high and low paid individuals and ASD, men (upper part) and women (lower part), 1984 - 1999
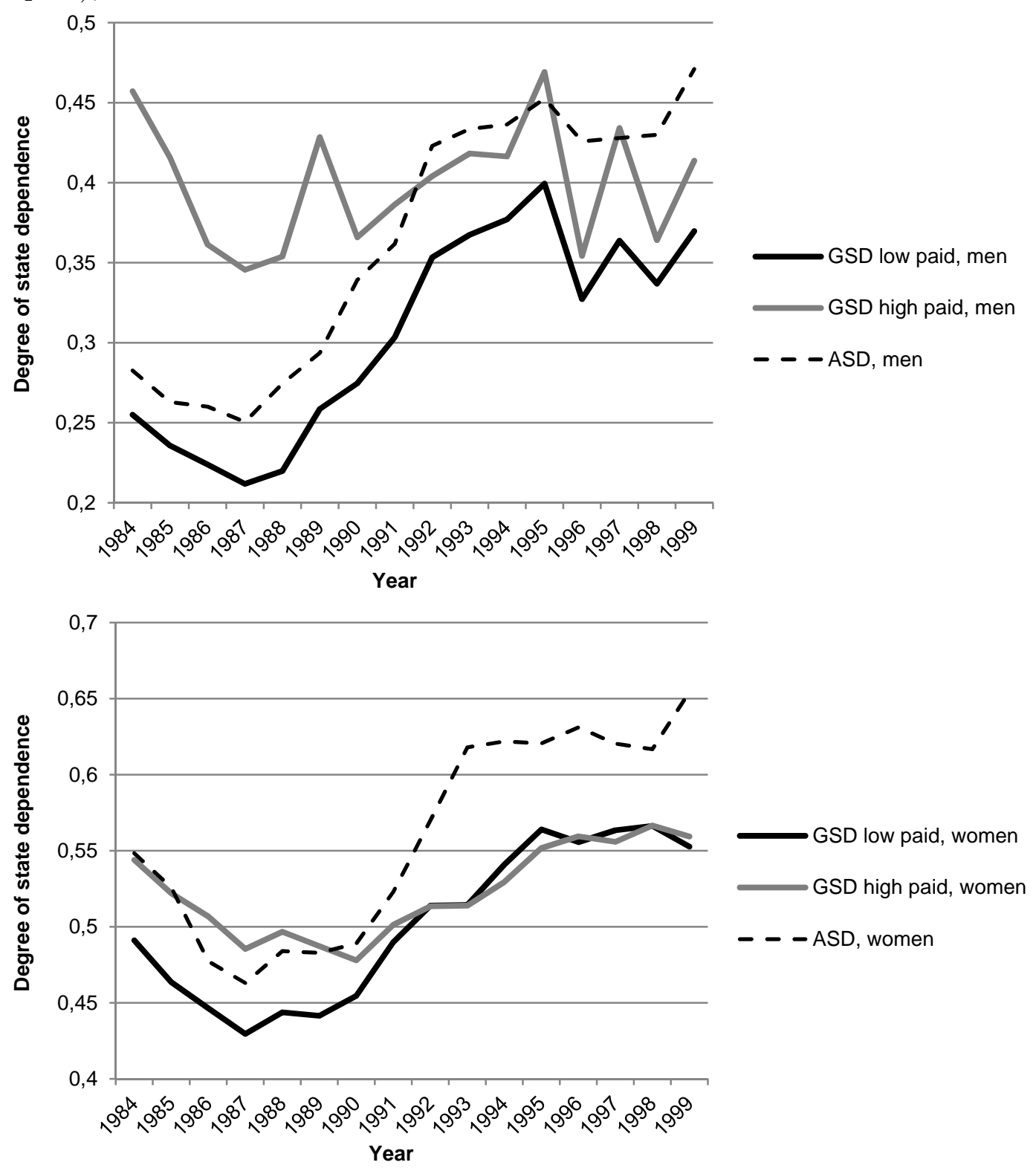

economic expansions than during recessions (e.g. Devereux and Hart 2006, Shin and Shin 2008). As Robin (2011) points out, this wage procyclicality is stronger for low-wage (and highest-wage) earners compared to median earners. ${ }^{15}$ Thus, the probability of ascending from a low to a high paid job might be higher in times of low unemployment leading to a positive correlation between the $G S D$ of low-wage workers and the unemployment rate.

\footnotetext{
${ }^{15}$ The main explanation for his finding is that when productivity increases, low-wage workers may credibly threaten to quit to unemployment as their reservation wage increases with aggregate productivity. Thus, firms may be forced to renegotiate wages up.
} 
Figure 10: Evolution of GSD and the unemployment rate, 1984 - 1999
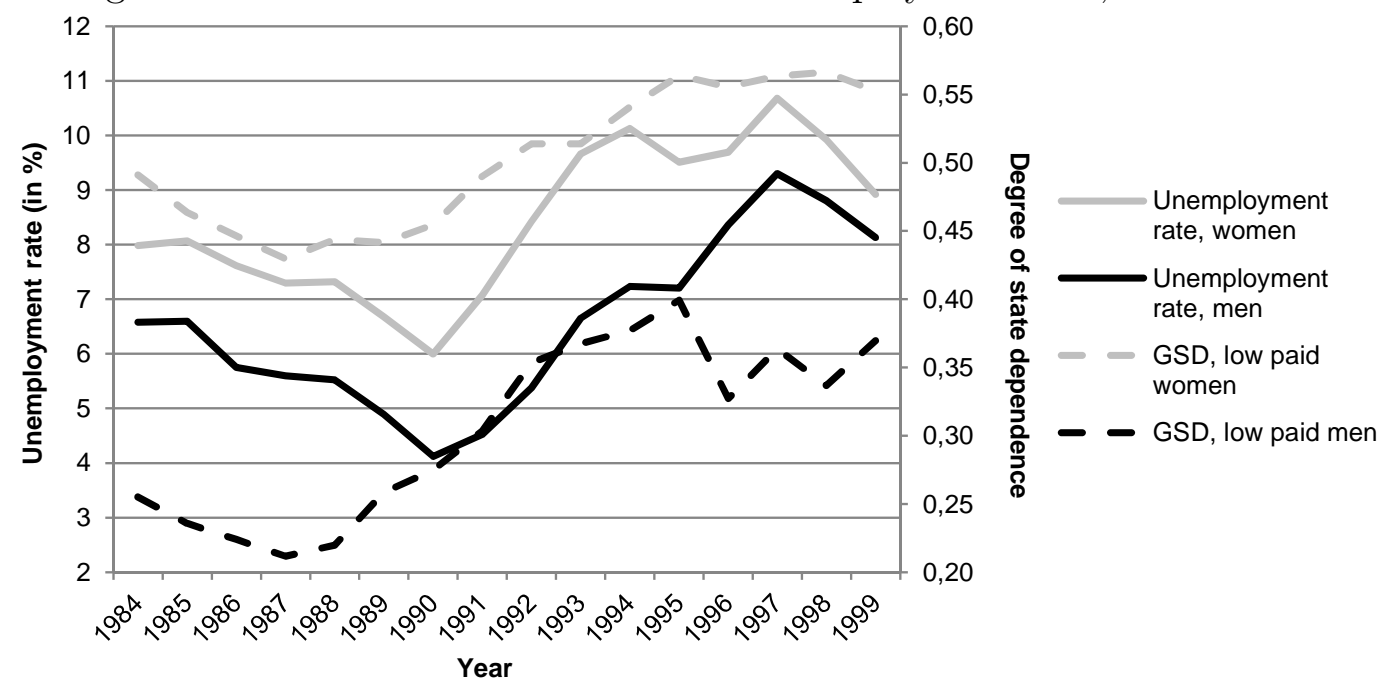

Although we are not able to make any causal inferences on the relationship between the extent of $G S D$ and the unemployment rate, Figure 10 provides some support for the similarity of the evolution of both factors. For both men and women, there is evidence that the evolution of the unemployment rate in year $t$ matches the evolution of low-wage workers' GSD (measuring the probability of sticking to the low-wage sector in $t+5$ ). The low paid women's decrease in GSD from 49 to 45 per cent between 1984 and 1990 was accompanied by a decrease in the female unemployment rate, which fell from 8 to 6 per cent during the same period. After 1990, the unemployment rate as well as the $G S D$ of the low paid rose distinctly. The positive association between the $G S D$ and the unemployment rate is confirmed by a high correlation coefficient of 0.87 , which is highly significant $(p=0.000)$. A positive relationship is also observed for men for whom the correlation coefficient of 0.55 is significant at the 5 per cent level $(p=0.026)$. The results therefore indicate that a higher unemployment rate fosters an increase in the probability of sticking to a low-wage job.

\subsubsection{Decomposing the evolution of genuine state dependence}

While the divergent development of $A S D$ and $G S D$ may be attributed to compositional shifts of the low relative to the high-wage sector, it does not permit us to infer any conclusions about the counterfactual evolution of $G S D$, had the low-wage workforce composition 
remained unchanged. Note that such a distinction is relevant as the evolution of $G S D$ still reflects both changes in the workforce composition as well as changes in the differential impacts of the observed covariates on the transition probabilities. In order to disentangle these effects, we employ decomposition techniques by Oaxaca (1973) and Blinder (1973) adapted to our non-linear framework:

$$
\begin{aligned}
G S D_{\mathrm{t}}-G S D_{\mathrm{t}-\mathrm{h}} & =\underbrace{\left(G S D_{\mathrm{t}}^{\mathrm{t}}-G S D_{\mathrm{t}}^{\mathrm{t}-\mathrm{h}}\right)}_{\text {coefficients effect }}+\underbrace{\left(G S D_{\mathrm{t}}^{\mathrm{t}-\mathrm{h}}-G S D_{\mathrm{t}-\mathrm{h}}^{\mathrm{t}}\right)}_{\text {characteristics effect }} \\
& =\underbrace{\left(G S D_{\mathrm{t}}^{\mathrm{t}}-G S D_{\mathrm{t}-\mathrm{h}}^{\mathrm{t}}\right)}_{\text {characteristics effect }}+\underbrace{\left(G S D_{\mathrm{t}-\mathrm{h}}^{\mathrm{t}}-G S D_{\mathrm{t}-\mathrm{h}}^{\mathrm{t}}\right)}_{\text {coefficients effect }},
\end{aligned}
$$

where $t$ and $t-h$ are two different points in time with $t>t-h$ and $G S D_{\mathrm{t}}^{\mathrm{t}}$ and $G S D_{\mathrm{t}-\mathrm{h}}^{\mathrm{t}-\mathrm{h}}$ estimated as described in equation (8). While the superscript marks the changes in coefficients, the subscript reflects changes in characteristics. Due to the cyclical evolution of $G S D$ over time, we apply the decomposition for two different time periods (1984 to 1989 and 1990 to 1999). The decompositions (10) and (11) differ with respect to the chosen counterfactual $G S D$. In equation (10), GS $D_{\mathrm{t}}^{\text {th- }}$ denotes how the $G S D$ would have evolved in $t-h$ (i.e. 1984 or 1990), had the composition of the workforce remained constant at its level in $t$ (i.e. 1989 or 1999). The term $G S D_{\mathrm{t}-\mathrm{h}}^{\mathrm{t}}$ in equation (11) instead uses predictions for individuals in $t$ (1984 or 1990) based on the coefficients in $t-h$ (1989 or 1999). The characteristics effect, thus, involves the part of the overall change between 1984 (1990) and 1989 (1999) which can be attributed to changes in observed characteristics of the individuals in the sample at given coefficients, whereas the coefficients effect captures the part which is due to changes in the coefficients at given characteristics.

Table 7 reports the results of the decompositions for the low-wage sector for the two time periods separately for men and women. Panel A shows the results for the base year 1999 (1989) resulting from equation (10), Panel B for the base year 1990 (1984), cp. equation (11). Turning first to the time period 1984-1989, the decomposition for men in column (1) shows that the change in observables would have actually favored an 
even higher increase in $G S D$ which has been overcompensated by the (negative) change in the coefficients. This result is valid independent of the chosen base year. For female workers, the change in coefficients was the driving force of the observed decline in $G S D$ between 1984 and 1989 although part of the observed decline in their GSD is accounted for by the characteristics effect (column (3)). This result holds irrespective of the base year chosen. During the 1990s, GSD rose for both low paid men and women (columns (2) and (4)). Irrespective of the base year chosen, the decompositions give very similar results across gender. While around 54 per cent of the increase in $G S D$ can be attributed to an unfavorable evolution of characteristics for both males and females with 1999 as base year (Panel A), the base year 1990 yields a contribution of the characteristics effect of 35 to 39 per cent (Panel B).

Table 7: Decomposition of the GSD over time for the low-wage workforce, by sex

\begin{tabular}{llcccc}
\hline & & \multicolumn{2}{c}{ Men } & \multicolumn{2}{c}{ Women } \\
Base year & & $1984 / 1989$ & $1990 / 1999$ & $1984 / 1989$ & $1990 / 1999$ \\
& & $(1)$ & $(2)$ & $(3)$ & $(4)$ \\
\hline \multirow{3}{*}{ A) 1989 / 1999} & Change in GSD & 0.4 & 9.5 & -5.0 & 9.8 \\
& Coefficients effect & -2.1 & 4.4 & -4.4 & 4.5 \\
& Characteristics effect & 2.5 & 5.1 & -0.5 & 5.3 \\
\hline \multirow{2}{*}{ B) $1984 / 1990$} & Change in GSD & 0.4 & 9.5 & -5.0 & 9.8 \\
& Coefficients effect & -1.5 & 6.2 & -3.9 & 6.0 \\
& Characteristics effect & 1.9 & 3.3 & -1.0 & 3.8 \\
\hline \hline
\end{tabular}

Note: All values in percentage points.

To sum up, this section has shown that the extent of $G S D$ slightly increased from 52 to 56 per cent for women, whereas it fluctuated quite stationarily around 40 per cent over time for men over our observation period. Differentiating between low and high-wage earners shows that especially the low-wage earners have experienced an increase in $G S D$ catching up with the level of high-wage earners at the end of the observation period. The fluctuation of GSD over time - mainly a decrease at the end of the 1980s followed by an increase in the early 1990s - matches for both men and women the evolution of the unemployment rate. The decomposition of GSD over time into a characteristics and a coefficients effect reveals for male workers that the change in GSD during the 1980s can be mostly attributed to a compositional shift. For female workers, it is rather the change in coefficients that accounts for the decrease in GSD. During the 1990s, the 
characteristics effect has become more important in determining $G S D$ for both sexes indicating a compositional shift towards more unfavorable characteristics among the low paid.

\section{Conclusions}

The purpose of the present paper was to study how individual wage mobility in the lowwage sector has changed over the last two decades of the twentieth century in western Germany. Using a large administrative data set, we first document that the low-wage sector has increased since the mid 1980s by around 14 per cent. The overall growth of the low-wage sector was accompanied by a distinct rise in the probability of sticking to a low-wage job for both men and women. However, the extent of persistence, as measured by the extent of aggregate state dependence $(A S D)$, varies greatly across different groups of individuals. Younger workers below 26 years, for example, face a much smaller risk of sticking to a low-wage job than the oldest age group (50-55 years). As the share of young workers among the low paid has decreased to a much larger extent than the corresponding fraction in the high-wage sector, this compositional shift might have contributed to the observed rise in $A S D$ over time.

In order to explore whether the observed decline in low-wage mobility is accounted for by compositional shifts or by an increase in "true" low-wage persistence, our analysis primarily seeks to infer conclusions about the evolution of "genuine"state dependence $(G S D)$. Genuine state dependence arises when low-wage employment today causes lowwage employment in the future for reasons of stigmatization or human capital depreciation. We compute a measure of genuine state dependence by contrasting each individual's transition probability of staying in the low-wage sector conditional on being initially low paid with the probability of entering the low-wage sector conditional on being initially high paid. The $G S D$ is then calculated by averaging these differences over the sample of workers with earnings retention. Hence, to obtain such predicted probabilities, we need to model low-pay transitions depending on a variety of low and high-wage workers' observable characteristics. In order to address the initial conditions problem and the 
endogeneity of earnings attrition, we estimate a series of annual trivariate probit models that account for the selection into low-wage employment and earnings retention.

Based upon the estimated transitions, our results show that between 1984 and 1999 male workers' $G S D$ - opposed to their increasing $A S D$ - exhibits a quite stationary development at a rate of about 40 per cent with some fluctuations over time. Concentrating only on those individuals in the low-wage sector, an increase in $G S D$ can be observed which is, however, clearly less accentuated than the rise in $A S D$. For women, there seems to have been a slight increase in $G S D$ during the 1990s from 47 to 56 per cent, which is observed for both high and low-wage earners. However, the increase is clearly less pronounced than the rise in $A S D$. The observed fluctuation of $G S D$ over time, mainly a decline in the late 1980s followed by an increase in the early 1990s, mirrors the evolution of the unemployment rate and indicates that a higher unemployment rate fosters an increase in the probability of sticking to a low-wage job for both men and women.

As the $G S D$ reflects both changes in the workforce composition as well as changes in the differential impacts of the observed covariates on the transition probabilities, we use decomposition techniques to disentangle these effects for the low-wage workforce. The decomposition of $G S D$ over time into a characteristics and a coefficients effect reveals for male workers that the change in $G S D$ during the 1980s can be mostly attributed to a change in characteristics. For female workers, it is rather the change in coefficients that accounts for the decrease in $G S D$. During the 1990s, the change in characteristics has become more important in determining $G S D$ for both sexes.

What do these results tell us about the ongoing discussion of decreasing wage mobility in the low-wage sector in Germany? Taken together, our analysis highlights the importance of accounting for possible compositional changes in the low-wage population. It also makes clear that the omission of such changing trends might lead to wrong inferences about the development of true low-wage persistence. In disentangling compositional shifts from changes in price effects, our findings show that - contrary to common perceptions the decline in low-wage mobility cannot be fully explained by an increase in "true"state dependence, but also by compositional changes. Depending on the base year chosen, we 
show that between 35 and 54 per cent of the increase in genuine state dependence during the 1990s can be attributed to compositional shifts towards more unfavorable observable characteristics among the low paid. Our results therefore lend strong support to the notion that appropriate policy interventions should aim at working against such compositional shifts by, e.g., improving low-wage earners' skills and intensifying older low paid employees' vocational training opportunities.

\section{References}

[1] Acemoglu, D. (2003), Cross-Country Inequality Trends, Economic Journal 113, F121F149.

[2] Bauer, T. K. and K. F. Zimmermann (1999), Assessment of Possible Migration Pressure and its Labour Market Impact Following EU Enlargement to Central and Eastern Europe, IZA Research Report No 3.

[3] Biewen, M. and S. Steffes (2008), Unemployment Persistence: Is There Evidence for Stigma Effects?, ZEW Discussion Paper No. 08-057.

[4] Biewen, M. (2009), Measuring State Dependence in Individual Poverty Histories When There is Feedback to Employment Status and Household Composition, Journal of Applied Econometrics 24, 1095-1116.

[5] Blinder, A.S. (1973), Wage Discrimination: Reduced Form and Structural Estimates, Journal of Human Resources 8, 436-455.

[6] Bönke, T., G. Corneo, H. Lüthen (2011), Lifetime Earnings Inequality in Germany, IZA Discussion Paper 6020.

[7] Bosch, G. and T. Kalina (2007), Niedriglöhne in Deutschland - Zahlen, Fakten, Ursachen, in: Bosch, G and C. Weinkopf (Eds.): Arbeiten für wenig Geld Niedriglohnbeschäftigung in Deutschland, Campus Verlag, 20-105.

[8] Buchinsky, M. and J. Hunt (1999), Wage Mobility in the United States, Review of Economics and Statistics 81, 351-368. 
[9] Cappellari, L. (2002), Do the Working Poor Stay Poor? An Analysis of Low Pay Transitions in Italy, Oxford Bulletin of Economics and Statistics 64, 87-110.

[10] Cappellari, L. and S.P. Jenkins (2003), Multivariate Probit Regression Using Simulated Maximum Likelihood, Stata Journal 3, 278-294.

[11] Cappellari, L. and S.P. Jenkins (2004), Modelling Low Income Transitions, Journal of Applied Econometrics 19, 593-610.

[12] Cappellari, L. and S. Jenkins (2006), Calculation of Multivariate Normal Probabilities by Simulation, with Applications to Maximum Simulated Likelihood Estimation, Stata Journal 6, 156-189.

[13] Cappellari, L. (2007), Earnings Mobility Among Italian Low-Paid Workers, Journal of Population Economics 20, 465-482.

[14] Cappellari, L. and S. Jenkins (2008), Estimating Low Pay Transition Probabilities Accounting for Endogenous Selection Mechanisms, Journal of the Royal Statistical Society Series 57, 165-186.

[15] Cardoso, A.R. (2006), Wage Mobility: Do Institutions Make a Difference?, Labour Economics 13, 387-404.

[16] Devereux, P.J. and R.A. Hart (2006), Real Wage Cyclicality of Job Stayers, WithinCompany Job Movers, and Between-Company Job Movers, Industrial \& Labor Relations Review 60, 105-119.

[17] Dickens, R. (2000), Caught in a Trap? Wage Mobility in Great Britain 1975-1994, Economica 67, 477-497.

[18] Drews, N. (2008), Das Regionalfile der IAB-Beschäftigtenstichprobe 1975-2004, Handbuch-Version 1.0.2, FDZ-Datenreport 2.

[19] Dustmann, C., Ludsteck, J. and U. Schönberg (2009), Revisiting the German Wage Structure, Quarterly Journal of Economics 124, 843-881. 
[20] European Commission (2004), Employment in Europe, Chapter 4: Labour Market Transitions and Advancement: Temporary Employment and Low-Pay in Europe.

[21] Federal Statistical Office Germany (2011), Fachserie 11, Reihe 4.3.1: Bildung und Kultur - Nichtmonetäre hochschulstatistische Kennzahlen 1980 - 2009, p.129

[22] Fitzenberger, B., Osikominu, A., R. Völter (2006), Imputation Rules to Improve the Education Variable in the IAB Employment Subsample, Journal of Applied Social Science Studies (Schmollers Jahrbuch) 126, 405-436.

[23] Gernandt, J. (2009), Decreasing Wage Mobility in Germany, ZEW Discussion Paper 09-044.

[24] Gosling, A., Machin, S., C. Meghir (2000), The Changing Distribution of Male Wages in the UK, Review of Economic Studies 67, 635-666.

[25] Gottschalk, P. (1997), Inequality, Income Growth, and Mobility: The Basic Facts, Journal of Economic Perspectives 11, 21-40.

[26] Heckman, J.J. (1981), The Incidental Parameters Problem and Problem of Initial Conditions in Estimating a Discrete Time - Discrete Data Stochastic Process, in: Manski, C.F. and D. McFadden (Eds.): Structural Analysis of Discrete Data with Economic Applications, MIT Press: Cambridge, Mass.

[27] Jovanovic, B. (1979), Job Matching and the Theory of Turnover, Journal of Political Economy 87, 972-990.

[28] Kohn, K. (2006), Rising Wage Dispersion, After All! The German Wage Structure at the Turn of the Century, IZA Discussion Paper 2098.

[29] Kopczuk, W., Saez, E. and J. Song (2010), Earnings Inequality and Mobility in the United States: Evidence from Social Security Data since 1937, Quarterly Journal of Economics 125, 91-128. 
[30] Lee, S. and R.A. Wilke (2009). Reform of Unemployment Compensation in Germany: A Nonparametric Bounds Analysis Using Register Data, Journal of Business and Economic Statistics 27, 193-205.

[31] Levy, F. and R.J. Murnane (1992), U.S. Earnings Levels and Earnings Inequality: A Review of Recent Trends and Proposed Explanations, Journal of Economic Literature 30, 1333-1381.

[32] Lockwood, B. (1991), Information Externalities in the Labour Market and the Duration of Unemployment, Review of Economic Studies 58, 733-753.

[33] Murphy, K.M. and Welch, F. (1990), Empirical Age-Earnings Profiles, Journal of Labor Economics 8, 202-229.

[34] Oaxaca, R. (1973), Male-Female Wage Differentials in Urban Labour Markets, International Economic Review 14, 693-709.

[35] OECD (1998), Employment Outlook, Chapter 2: Making the Most of the Minimum: Statutory Minimum Wages, Employment and Poverty.

[36] Omori, Y. (1997): Stigma effects of Nonemployment, Economic Inquiry 35, 394-416.

[37] Prasad, E. (2004), The Unbearable Stability of the German Wage Structure: Evidence and Interpretation, IMF-Staff Paper 51, Washington D.C.

[38] Rhein, T., Gartner, H. and G. Krug (2005), Niedriglohnsektor - Aufstiegschancen für Geringverdiener verschlechtert, IAB Kurzbericht 3, 1-5.

[39] Riphahn, R.T. and D.D. Schnitzlein (2011), Wage Mobility in East and West Germany, IZA Discussion Paper 6246.

[40] Robin, J.M. (2011), On the Dynamics of Unemployment and Wage Distributions, Econometrica 79, 1327-1355.

[41] Shin D. and K. Shin (2008), Why Are the Wages of Job Stayers Procyclical?, Macroeconomic Dynamics 12, 1-21. 
[42] Stewart, M.B. and J.K. Swaffield (1999), Low Pay Dynamics and Transition Probabilities, Economica 66, 23-42.

[43] Uhlendorff, A. (2006), From No Pay to Low Pay and Back Again? A Multi-State Model of Low Pay Dynamics, IZA Discussion Paper 2482.

[44] Wooldridge, J.M. (2005), Simple Solutions to the Initial Conditions Problem in Dynamic, Nonlinear Panel Data Models with Unobserved Heterogeneity, Journal of Applied Econometrics 20, 39-54. 


\section{Appendix}

\section{Appendix A: Figures}

Figure A1: Aggregate state dependence by tenure group, 1984 - 1999

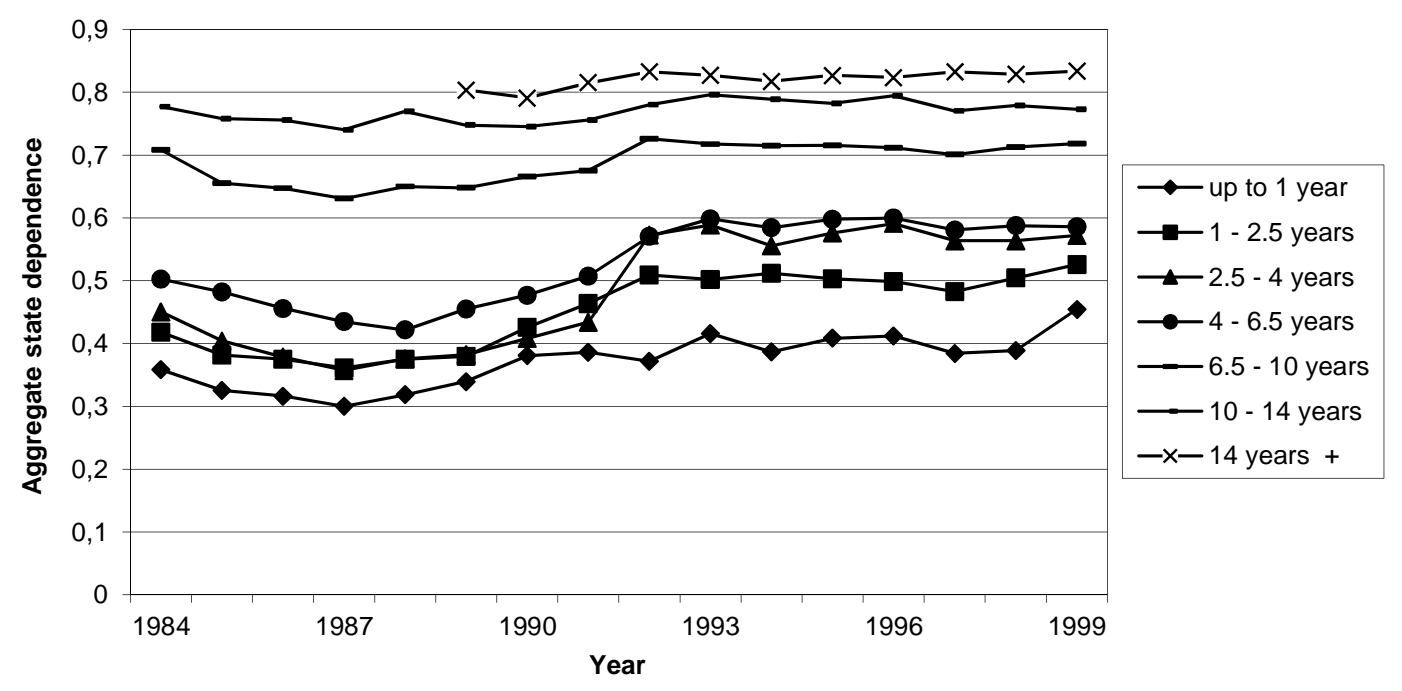

Figure A2: Mean share of low-wage earners by tenure group and sex, $1984-2002$

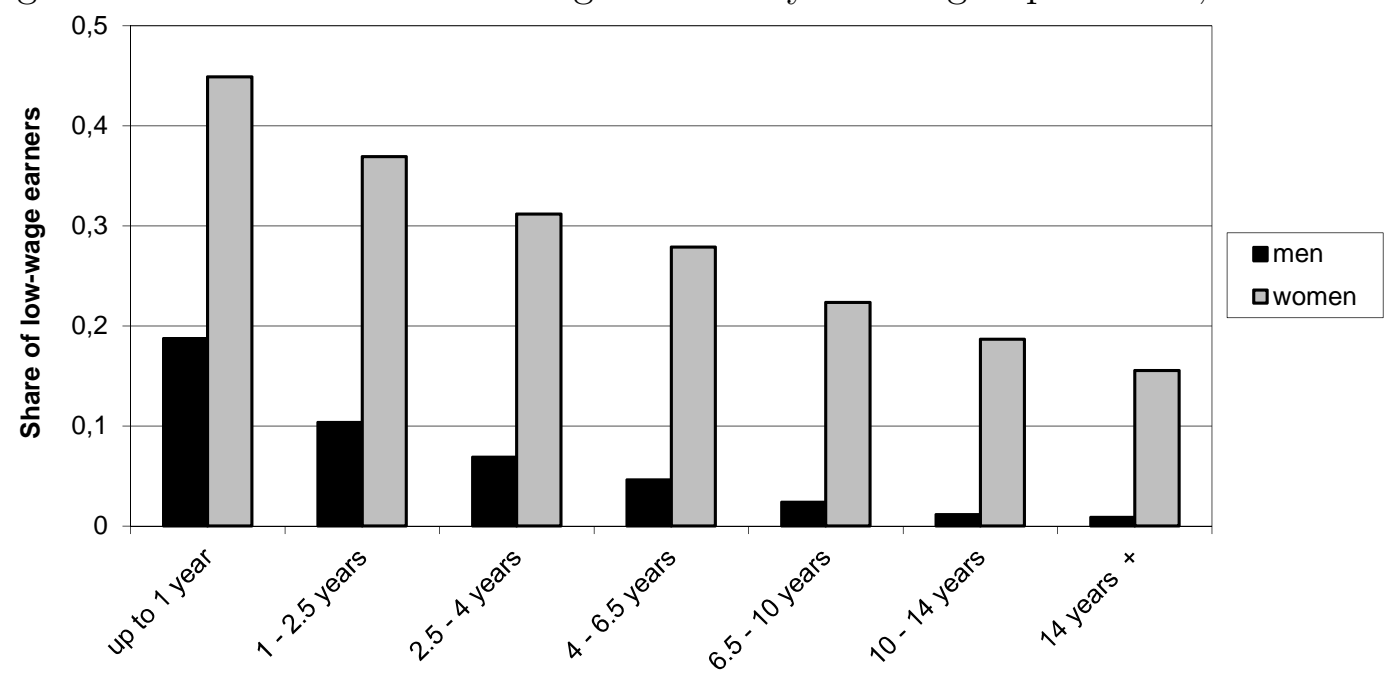


Figure A3: Aggregate state dependence by degree and sex, total population, 1984 - 1999

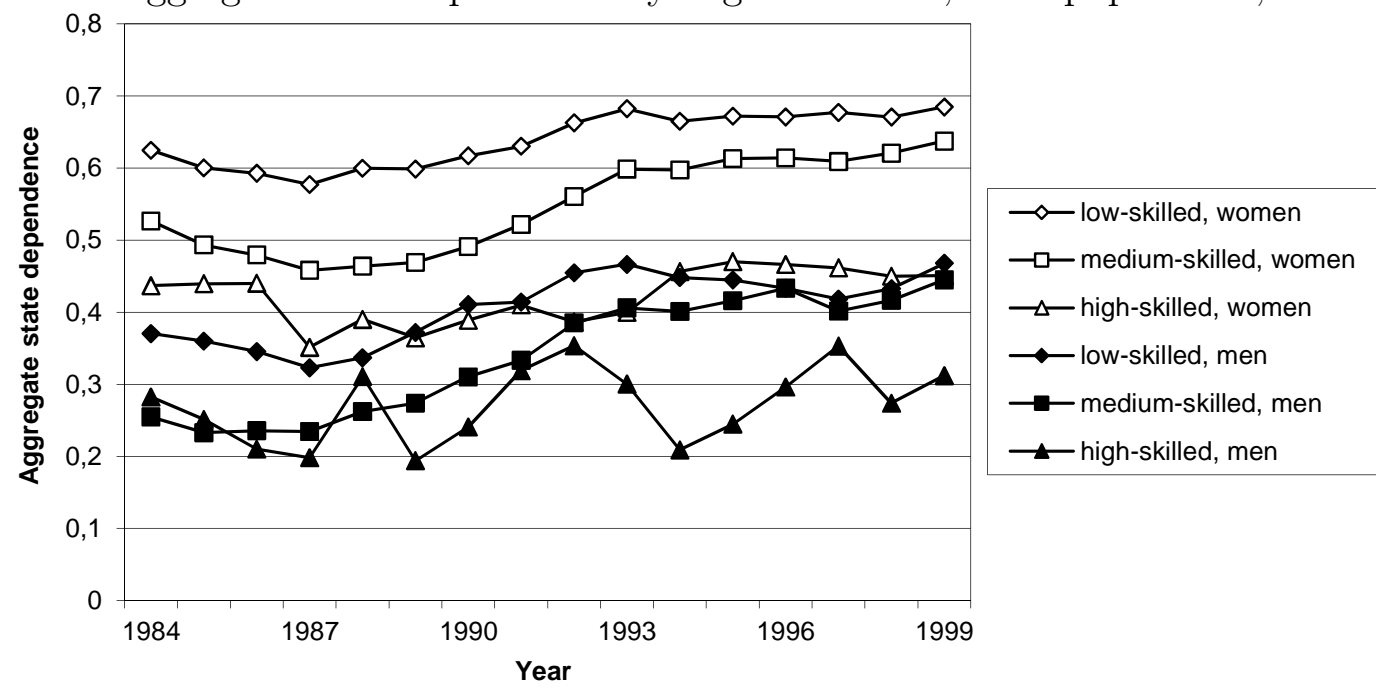

Figure A4: Mean share of low-wage earners by degree and sex, 1984 - 2002

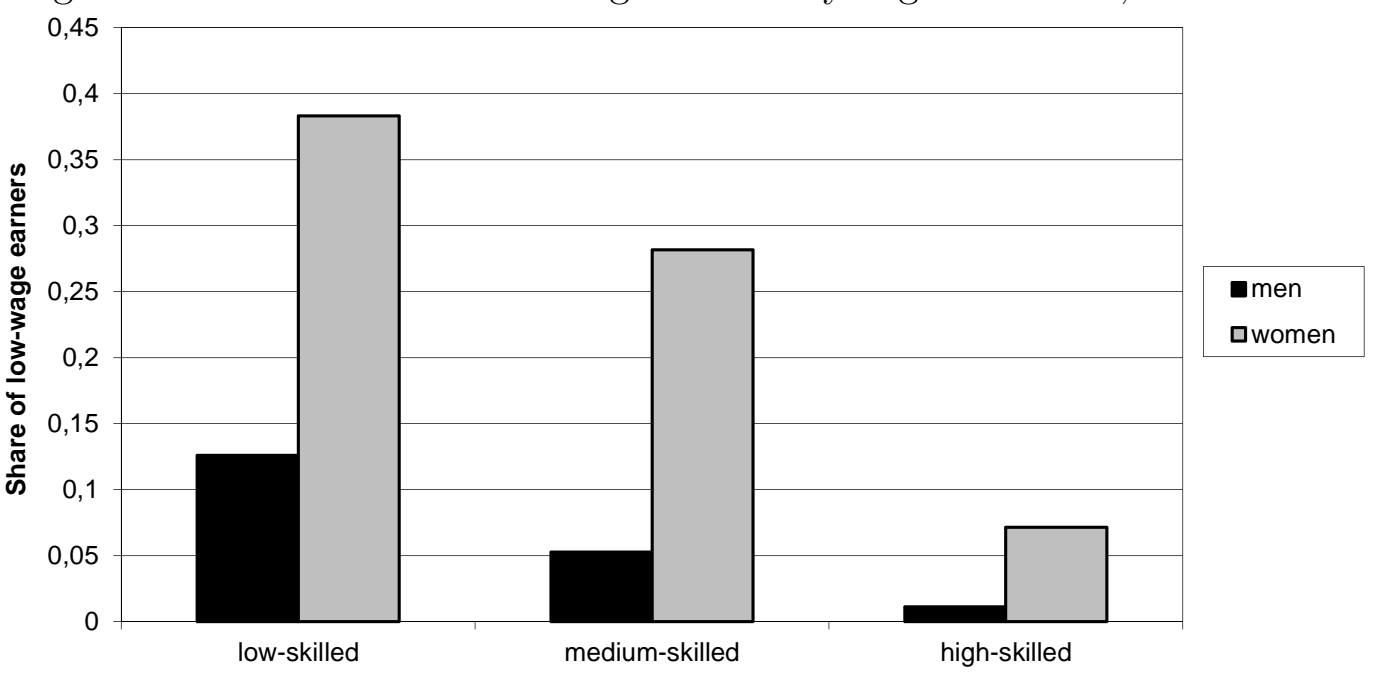


Figure A5: Aggregate state dependence by nationality and sex, total population, 1984 1999

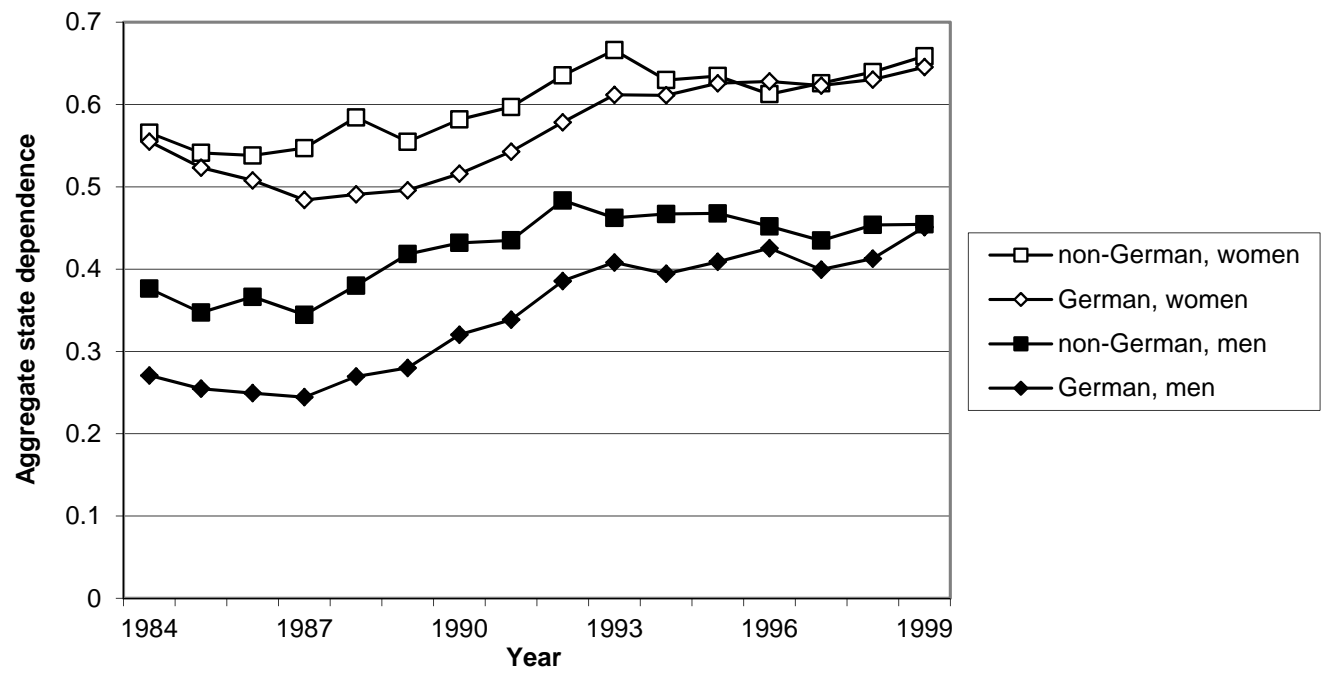

Figure A6: Aggregate state dependence by occupation and sex, total population, 1984 1999

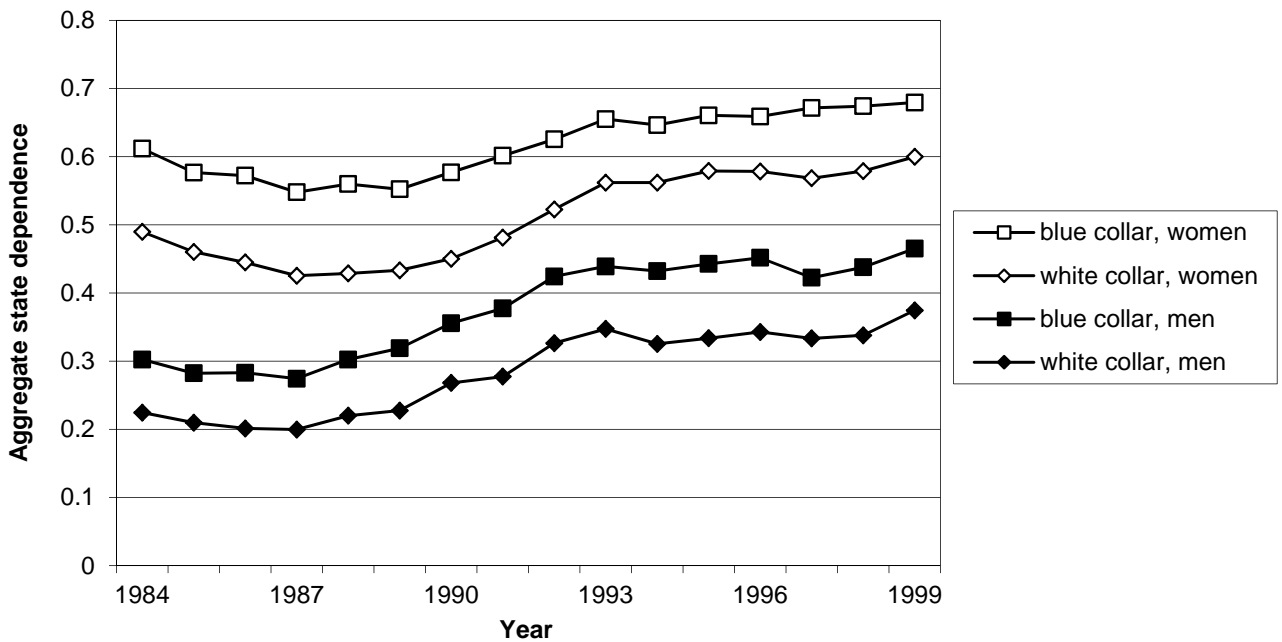


Figure A7: Evolution of the composition of sex in the low- and high-wage sector, 1984 2002

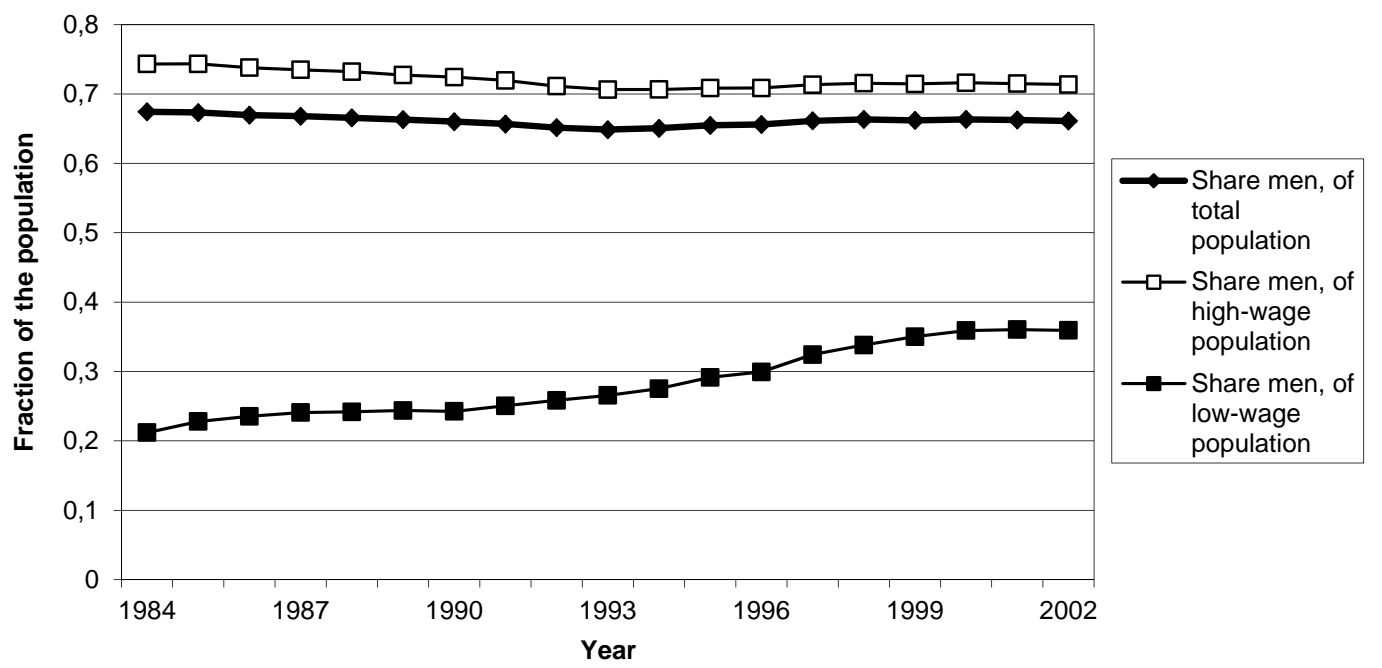

Figure A8: Evolution of the skill composition in the low- and high-wage sector, 1984 2002, women

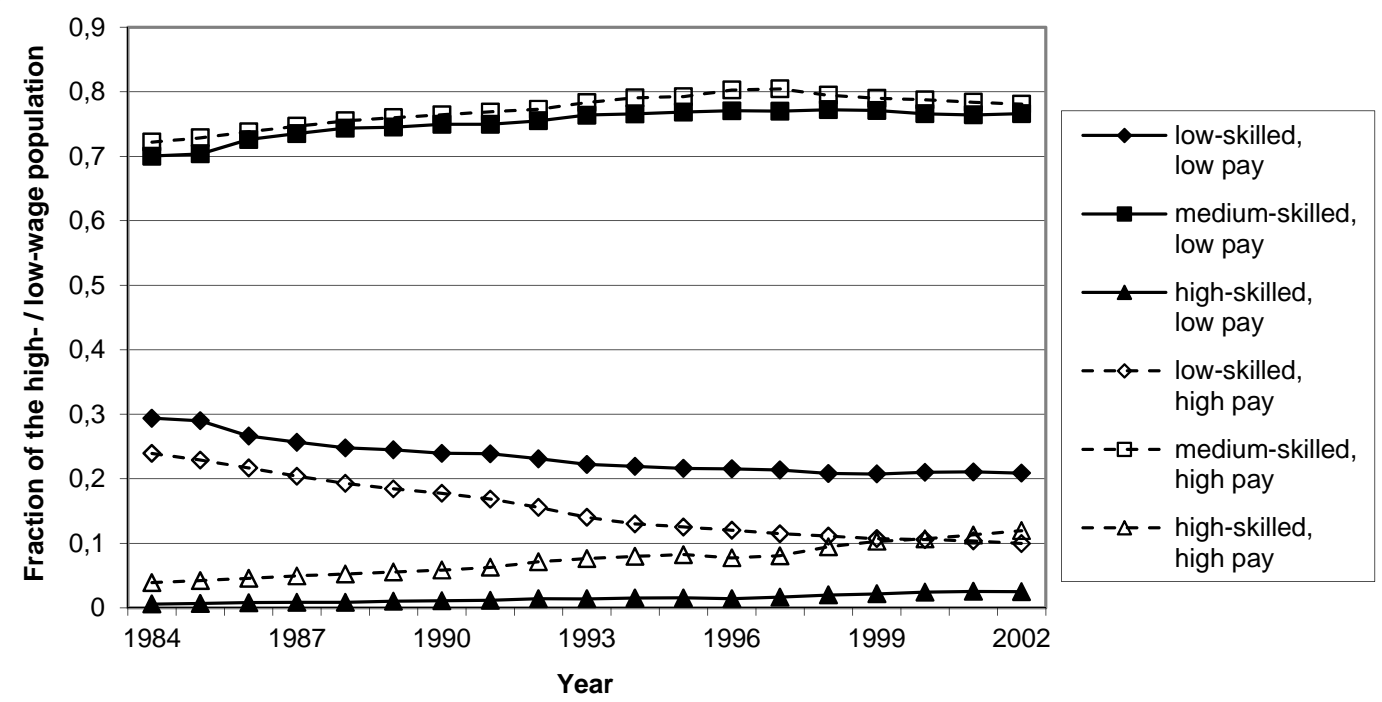


Figure A9: Evolution of the skill composition in the low- and high-wage sector, 1984 2002, men

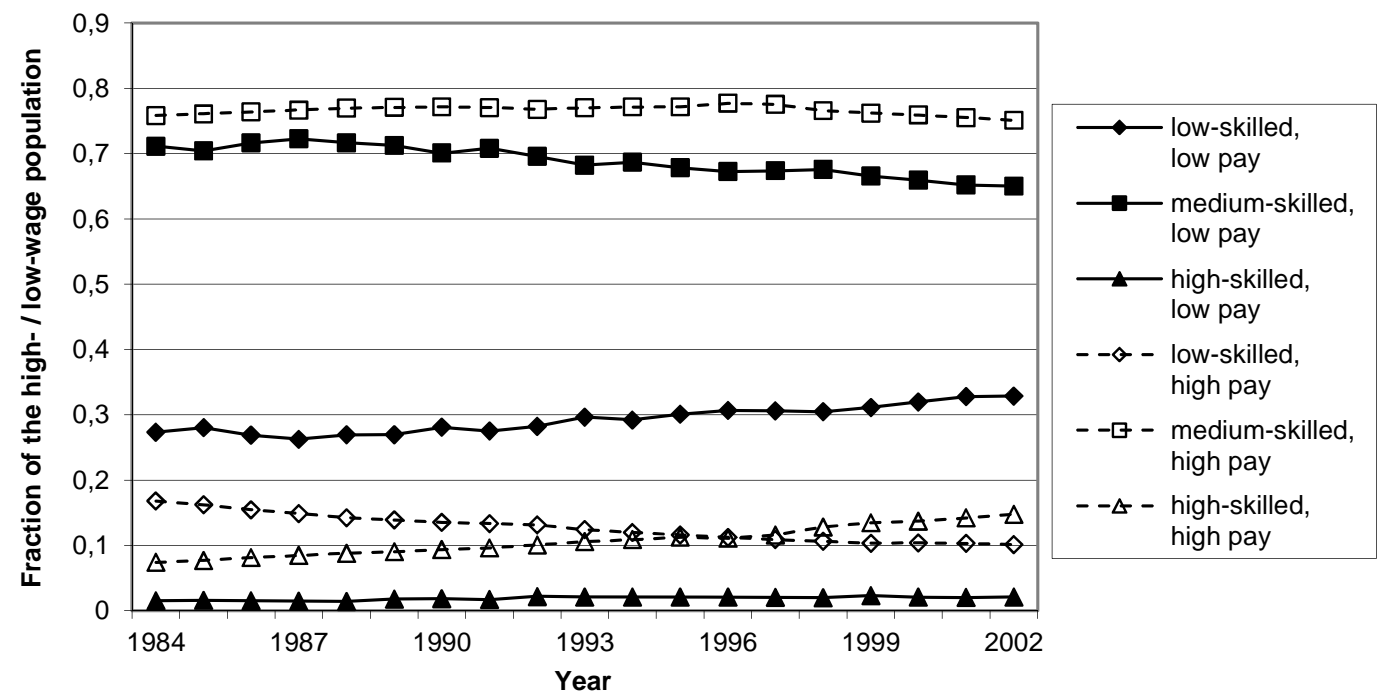

Figure A10: Evolution of the low- and high-wage sector by collar and sex, 1984 - 2002

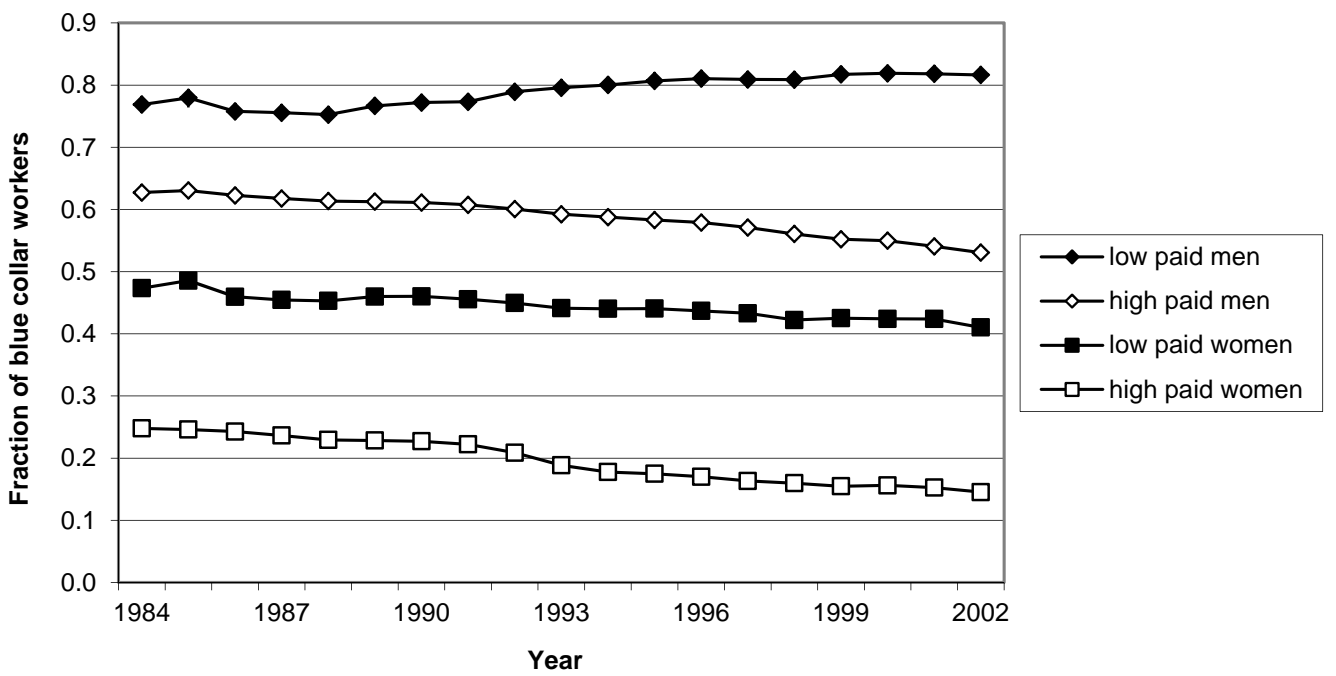


Figure A11: Evolution of the low- and high-wage sector by nationality and sex, 1984 2002

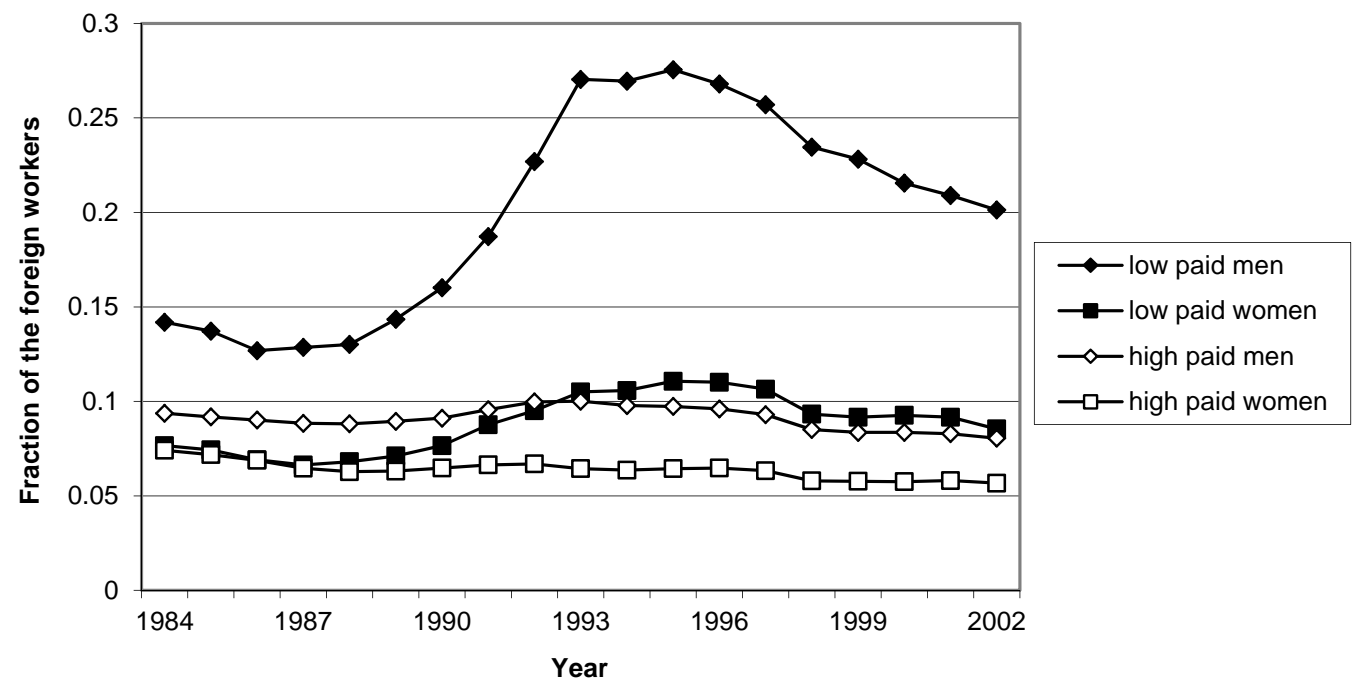




\section{Appendix B: Tables}

Table B1: Description of the variables used in the analysis

\begin{tabular}{|c|c|}
\hline Variable & Definition \\
\hline Age & Age (20-55 years) categorized in seven sub-groups \\
\hline Tenure & Sum of all previous days of employment at current employer \\
\hline Tenure squared & Square of sum of all previous days of employment \\
\hline Nationality & Dummy $=0$ if German \\
\hline Medium-skilled ${ }^{1)}$ & Dummy $=1$ if completed vocational training but no university degree \\
\hline High-skilled & Dummy $=1$ if university degree \\
\hline Previous occupation status & $\begin{array}{l}\text { Dummy }=1 \text { if previously employed, Dummy }=0 \text { if previously } \\
\text { un-/non- or part-time employed or in vocational training }\end{array}$ \\
\hline Total unemployment duration $\left.{ }^{2}\right)$ & Sum of all previous days of unemployment \\
\hline Total non-employment duration & Sum of all previous days of non-employment \\
\hline Number of unemployment spells & Sum of all previous unemployment spells \\
\hline Number of non-employment spells & Sum of all previous non-employment spells \\
\hline Number of previous employers & Sum of all previous employers \\
\hline Previous employment interruption & Dummy $=1$ if recall from current employer \\
\hline Number of empl. interruptions & Sum of all previous recalls at current employer \\
\hline Change of employer & Dummy $=1$ if employer or employment status changes \\
\hline Profession & Dummy $=1(=0)$ if blue-collar (white-collar) worker \\
\hline 6 occupation dummies & Either agrarian, salary, sale, clerical, service or production worker \\
\hline 16 sector dummies & Two-digit sectors (for categorization see Drews, 2008, pp. 67) \\
\hline 11 regional dummies & The 10 Western German states plus West-Berlin (until 1990) \\
\hline Low wage in t (1989-2004) & Dummy $=1$ if gross daily wage in $t<2 / 3$ of the median wage ${ }^{3)}$ \\
\hline Low wage in t-5 (1984-1999) & Dummy $=1$ if gross daily wage in $t-5<2 / 3$ of the median wage \\
\hline Retention in $\mathrm{t}$ & Dummy $=1$ if full-time employment status is observed in $t-5$ and $t$ \\
\hline
\end{tabular}

1) To improve the education variable, we use the imputation rules derived by Fitzenberger et al. (2006).

${ }^{2)}$ Following the procedure proposed by Lee and Wilke (2009), involuntary unemployment is defined as comprising all continuous periods of transfer receipt. Gaps between periods of transfer receipt or gaps between transfer receipt and a new employment spell may not exceed four weeks, otherwise these periods are considered as non-employment spells (involving voluntary unemployment or an exit out of the social security labor force). Similarly, gaps between periods of employment and transfer receipt are treated as involuntary unemployment as long as the gap does not exceed six weeks, otherwise the gap is treated as non-employment.

3) Due to the introduction of the Euro in 1999, all wages before 1999 are transformed from Deutschmark into Euros at a rate of $1 €=1.95583$ Deutschmark. Since the wage variable delivers unrealistic daily wages at the lower end of the wage distribution, we exclude all observations with earnings of less than $16 €$ per day (in prices of 1995). 
Table B2: Mean values of the characteristics used in the estimation, by wage sector

\begin{tabular}{lcccc}
\hline & \multicolumn{2}{c}{ High wage } & \multicolumn{2}{c}{ Low wage } \\
& Mean & Std. Dev. & Mean & Std. Dev. \\
\hline Females & 0.28 & 0.45 & 0.72 & 0.45 \\
Age (in years) & 37.50 & 9.58 & 33.81 & 10.48 \\
Low-skilled & 0.13 & 0.34 & 0.25 & 0.43 \\
Medium-skilled & 0.77 & 0.42 & 0.73 & 0.44 \\
High-skilled & 0.10 & 0.30 & 0.02 & 0.12 \\
Tenure & $2,797.02$ & $2,200.56$ & $1,571.11$ & $1,646.39$ \\
Being foreign & 0.08 & 0.28 & 0.12 & 0.33 \\
Blue-collar worker & 0.48 & 0.50 & 0.54 & 0.50 \\
Previously full-time employed & 0.42 & 0.49 & 0.23 & 0.42 \\
Previous employment interruption (=1) & 0.22 & 0.41 & 0.18 & 0.39 \\
Number of empl. interruptions & 0.31 & 0.96 & 0.29 & 1.05 \\
Change of employer & 0.10 & 0.30 & 0.21 & 0.41 \\
Number of previous employers & 3.11 & 2.59 & 3.44 & 3.11 \\
Previous unemployment duration (in days) & 101.62 & 258.33 & 163.42 & 351.63 \\
Number of unemployment spells & 0.65 & 1.56 & 0.86 & 1.66 \\
Previous non-employment duration (in days) & 368.38 & 808.71 & 727.03 & $1,297.24$ \\
Number of non-empl. spells & 0.96 & 1.72 & 1.50 & 2.46 \\
Retention after five years & 0.78 & 0.42 & 0.56 & 0.50 \\
Low paid five years ago & 0.02 & 0.16 & 0.55 & 0.50 \\
\hline Observations & $4,866,868$ & & 766,533 \\
\hline
\end{tabular}

Table B3: Share of selected characteristics in per cent among the total low-wage population

\begin{tabular}{lcccc}
\hline & \multicolumn{2}{c}{ Males } & \multicolumn{2}{c}{ Females } \\
& 1984 & 2002 & 1984 & 2002 \\
\hline Age 20-25 & 52 & 24 & 40 & 19 \\
Age 51-55 & 5 & 8 & 7 & 11 \\
Low-skilled & 27 & 33 & 29 & 21 \\
Medium-skilled & 71 & 65 & 70 & 77 \\
High-skilled & 2 & 2 & 1 & 3 \\
Being foreign & 14 & 20 & 8 & 9 \\
Blue-collar worker & 77 & 82 & 47 & 41 \\
Previously full-time employed & 16 & 25 & 20 & 25 \\
\hline Observations & 7,760 & 15,170 & 28,858 & 27,053 \\
\hline
\end{tabular}




\section{Appendix C: Derivation of the marginal effect}

In order to be able to interpret the estimation results, we report the marginal effects (ME) showing the impact on the relevant probabilities of a change in the chosen covariate. For a dummy variable, the ME is calculated as a change in the probability resulting from a change in the indicators value from zero to one, holding all other covariates fixed at their sample median values. ME for continuous variables are usually estimated by evaluating the partial derivative, which is equal to the corresponding coefficient multiplied by an evaluation of the normal density function. However, the computation is not straightforward here because the transition probabilities are conditional in nature (e.g. the probability of low pay in $t$ conditional of being low paid in $t-5)$. To clarify this point, the conditional probabilities are given by:

$$
e_{i t} \equiv\left[\operatorname{Pr}\left(L_{i t}=1 \mid L_{i t-5}=1\right)\right]=\left[\Phi_{2}\left(z_{i t-5} \widehat{\gamma}_{1}, x_{i t-5} \widehat{\beta} ; \rho_{2}\right) \Phi\left(x_{i t-5} \widehat{\beta}\right)\right]
$$

and

$$
\left.f_{i t} \equiv\left[\operatorname{Pr}\left(L_{i t}=1 \mid L_{i t-5}=0\right)\right]=\Phi_{2}\left(z_{i t-5} \widehat{\gamma}_{2},-x_{i t-5} \widehat{\beta} ;-\rho_{2}\right) \Phi\left(-x_{i t-5} \widehat{\beta}\right)\right]
$$

As is evident from eqs. (12) and (13), a change in the value of a covariate may affect both the numerator and denominator of the conditional probabilities. In order to deal with this issue, we adopt the procedure suggested by Stewart and Swaffield (1999) (see also Cappellari (2007) and Cappellari and Jenkins (2008)) by keeping the elements of $x_{i t-5}$ fixed. To do so, we first predict the low-pay probability in $t-5$ for all low paid individuals and take the average over these values - denoted as $q$. By inserting $w=\Phi^{-1}(q)$ into eq. (12), we obtain $\Phi_{2}\left(z_{i t-5} \widehat{\gamma}_{1}, w ; \rho_{2}\right) / q$. This expression is used to calculate ME as deviations between the conditional probabilities for a reference person and hypothetical probabilities induced by changing each covariate by an unit. For the reference person, we set continuous covariates to the sample median values and dummy variables to zero. The same procedure is applied to $f_{i t}$. 